\title{
Analysis of Water Surplus at the Lunar Outpost
}

\author{
Edgardo Santiago-Maldonado ${ }^{1}$ \\ NASA Kennedy Space Center, Cape Canaveral, FL, 32899 \\ Robert M. Bagdigian ${ }^{2}$ \\ NASA Marshall Space Flight Center, Huntsville, AL, 35812 \\ Patrick J. George ${ }^{3}$, David W. Plachta ${ }^{4}$, Homer J. Fincannon ${ }^{5}$ \\ NASA Glenn Research Center, Cleveland, OH, 44135 \\ Sharon A, Jefferies ${ }^{6}$, Jennifer P. Keyes ${ }^{7}$, David M. Reeves ${ }^{8}$ \\ NASA Langley Research Center, Hampton, VA, 23681 \\ And \\ Hilary R. Shyface ${ }^{9}$ \\ Analytical Mechanics Associates Inc., Hampton, VA, 23681
}

This paper evaluates the benefits to the lunar architecture and outpost of having a surplus of water, or a surplus of energy in the form of hydrogen and oxygen, as it has been predicted by Constellation Program's Lunar Surface System analyses. Assumptions and a scenario are presented leading to the water surplus and the revolutionary surface element options for improving the lunar exploration architecture and mission objectives. For example, some of the elements that can benefit from a water surplus are: the power system energy storage can minimize the use of battery systems by replacing batteries with higher energy density fuel cell systems; battery packs on logistics pallets can also be minimized; mobility asset power system mass can be reduced enabling more consumables and extended roving duration and distance; small robotic vehicles (hoppers) can be used to increase the science exploration range by sending round-trip robotic missions to anywhere on the Moon using in-situ produced propellants.

$\begin{array}{ll} & \\ \text { AAMA } & =\text { Active-Active Mating Adapter } \\ \text { ACL } & =\text { Airlock-derived Logistic Module } \\ \text { ATHLETE } & =\text { All-Terrain Hex-Legged Extra-Terrestrial Explorer } \\ \text { CMAT } & =\text { Campaign Manifest Analysis Tool } \\ \text { CMC } & =\text { Crew Mobility Chassis } \\ \text { CUR } & =\text { Constellation Unpressurized Rover } \\ \triangle V & =\text { Change in velocity } \\ \text { ECLSS } & =\text { Environment Control and Life Support System } \\ \text { EVA } & =\text { Extra-Vehicular Activity }\end{array}$

\footnotetext{
${ }^{1}$ Chemical Engineer, Engineering Directorate, Surface Systems Office, MS NE-S2. AIAA Member

${ }^{2}$ Chief, Environmental Control and Life Support Development Branch, MS ES62.

${ }^{3}$ LSS Power System Lead, GRC Space Flight System, Mail Stop: 77-5.

${ }^{4}$ Senior Research Engineer, Power and In-Space Propulsion Division, MS 301-3

${ }^{5}$ Electrical Engineer, Power Systems Branch, MS 54-7.

${ }^{6}$ Research Aerospace Engineer, Space Mission Analysis Branch, MS 462, Senior Member.

${ }^{7}$ Aerospace Engineer, Systems Analysis \& Concepts Directorate, Space Mission Analysis Branch, MS 462.

${ }^{8}$ Aerospace Engineer, Systems Analysis \& Concepts Directorate, Space Mission Analysis Branch, MS 462.

${ }^{9}$ Engineer, System Analysis \& Concepts Directorate MS 462.
}

American Institute of Aeronautics and Astronautics 


$\begin{array}{ll}\text { FSPS } & =\text { Fission Surface Power System } \\ g & =\text { gravity }\left(9.8 \mathrm{~m} / \mathrm{s}^{2}\right) \\ \text { Isp } & =\text { Specific Impulse } \\ \text { ISRU } & =\text { In-Situ Resource Utilization } \\ \text { LCH }_{4} & =\text { Liquid Methane } \\ \text { LER } & =\text { Lunar Electric Rover } \\ \text { ln } & =\text { Natural logarithm } \\ \text { LOx } & =\text { Liquid Oxygen } \\ \text { LSAM } & =\text { Lunar Surface Access Module } \\ \text { LSS } & =\text { Lunar Surface System } \\ \text { LSMS } & =\text { Lunar Surface Manipulator System } \\ \text { OPS } & =\text { Oxygen Production System } \\ \text { PCM } & =\text { Pressurized Crew Module } \\ \text { PCT } & =\text { Portable Communication Terminal } \\ \text { PEM } & =\text { Pressurized Excursion Module } \\ \text { PLM } & =\text { Pressurized Logistic Module } \\ \text { PSU } & =\text { Power \& Support Unit } \\ \text { PUP } & =\text { Portable Utility Pallet } \\ \text { RA } & =\text { Robotic Assistant } \\ \text { RFC } & =\text { Regenerative Fuel Cell } \\ \text { SOD } & =\text { Small Offloading Device } \\ \text { SPR } & =\text { Small Pressurized Rover } \\ \text { SSU } & =\text { Structural Support Unit } \\ \text { STM } & =\text { Suitport Transfer Module }\end{array}$

\section{Introduction}

TASA's Lunar Surface System (LSS) Project Office, part of the Constellation Program, has been investigating 1 the design and development of various elements that are the building blocks for the Lunar Outpost and Architecture. These building blocks or elements, habitats, mobility chassis, power systems, logistics pallets, resource utilization systems, life support systems, and others, and their variations can be arranged in many ways. LSS has designed a framework in order to perform trade studies to analyze a handful of scenarios defining how to build the lunar outpost. While the outpost has a primary objective, its buildup can be accomplished with different focuses, which results in the various permutations of scenarios. Some of the scenarios analyzed include an: (a) "emphasis on habitat" in which the outpost is focused on a stationary base with minimum mobility, (b) "emphasis on mobility" in which the outpost is capable of traversing long distances, (c) "emphasis on power" to study the effect of the various power generation systems. Combining scenarios by selecting the best aspects of each is useful to optimize the outpost design.

These scenarios have provided significant information, challenges, and solutions that increase the efficiency of the lunar outpost. As a result, significant technology development needs have evolved from these analyses. More recently, and the focus of this paper, is the indication of water surplus during the build-up of the outpost and subsequent permanent human presence. Two major assumptions that contribute to the surplus of water are the advanced exploration life support systems ${ }^{1}$ that provides water and oxygen recovery and propellant scavenging ${ }^{2}$ from the hydrogen-oxygen lander descent stage propellant tanks. The advanced life support system captures and regenerates water and oxygen from metabolic wastes and carbon dioxide. The propellant scavenging uses the residual propellant after the lander mission is completed to run fuel cells producing power and water, which is easier stored than cryogenic propellants. The production of water from propellant scavenging is augmented by the use of in-situ produced oxygen, since oxygen is depleted from the propellant tanks before hydrogen.

Various elements can be significantly modified based on the availability of excess water to optimize their design, minimizing the overall mass launched from Earth, and thus decreasing logistics requirements. These elements include: (1) the power system energy storage which can minimize the use of battery systems by replacing batteries with higher energy density fuel cells, (2) logistics pallets equipped with power systems can minimize the use of batteries, (3) mobility systems can reduce the power system mass and pack more consumables to extend roving duration and distance, (4) small robotic vehicles (i.e. hoppers) can be introduced and used to increase the science 
exploration range by sending round-trip robotic missions to anywhere on the Moon using in-situ produced propellants.

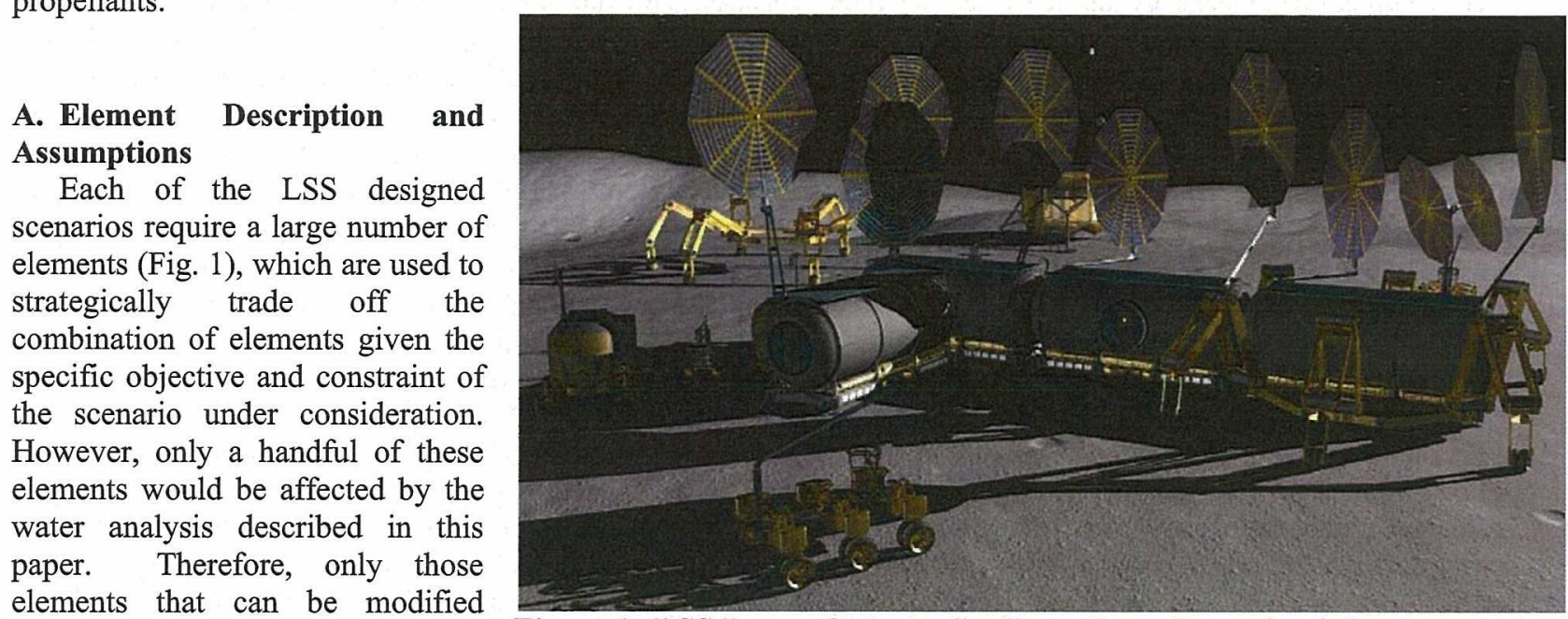
elements that can be modified providing benefits to the lunar campaign will be discussed in

Figure 1. LSS Lunar Outpost Configuration. Example of elements required to build a lunar outpost. detail. For a full description of the LSS lunar architecture characteristics and extended element definition, the reader is encouraged to review Ref. 3.

\section{Lunar Electric Rover (LER)}

The Crew Mobility Chassis (CMC), shown in Fig. 2 (a), consist of a versatile mobility chassis used for all crew mobility needs, ISRU resources gathering, small payloads hauling, science exploration, and other outpost operations. The CMC can perform any mobility role such as: manned or unmanned unpressurized rover, pressurized rover, mobile ISRU OPS, mobile power system, and others. In its pressurized rover configuration, the CMC is known as Small Pressurized Rover (SPR) shown in Fig. 2 (b). LER and SPR would be used throughout this paper interchangeably to mean the integrated $\mathrm{CMC}$ and pressurized crew cabin element.

The baselined LER design is powered by a battery energy storage and power system, which requires an external power regeneration system to recharge the batteries (e.g. PSU and PUP discussed below). In a SPR configuration, the energy storage capacity of the element is designed to include the loads required for the mobility chassis as well as the loads for the pressurized crew cabin. One of the major energy storage and power system requirement drivers is the energy required to support a crew of two during a 14-day excursion mission. During the excursion traverse, the LER will require the support of the Portable Utility Pallet element, as described later in this paper, to recharge the battery system.

a)

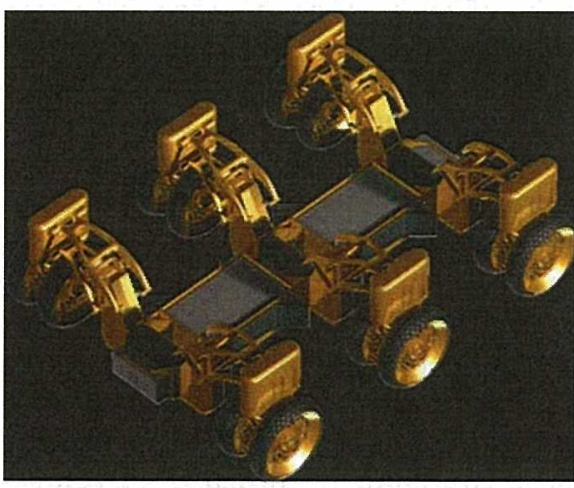

b)

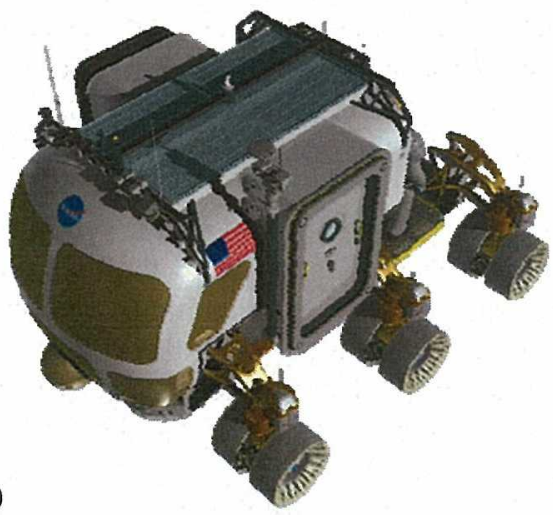

Figure 2. Lunar Electric Rover. a) Crew Mobility Chassis, and b) Lunar Electric Rover (aka SPR) 


\section{Energy Storage and Power System}

The main classes of energy storage that have been considered for the lunar surface are those based on batteries and fuel cells. These energy storage components are used in surface elements such as the Altair Lander, the Power and Support Unit (PSU), the Lunar Electric Rover (LER), the Portable Utility Pallet (PUP) and the All-Terrain HexLegged Extra-Terrestrial Explorer (ATHLETE) as well as for small rovers and astronaut suits. All elements are designed to have mobility, although some are predominately stationary for extended time periods. The Altair Lander transports crew and cargo to/from the lunar surface and includes both a fuel cell and battery system. The PSU provides very high energy storage, a solar array power source, and other functionality to various elements. The LER, the predominant vehicle for transporting crew on the lunar surface, is designed to operate only on energy storage (the baseline has been batteries) with no power source to supplement or recharge this energy. The PUP was designed to enable the LER to carry such a power source capability for recharging, as well as more batteries (or reactants/tanks for a fuel cell system). The ATHLETE and other small rovers and astronaut suits nominally assume batteries for their energy storage, although fuel cells have been considered for the ATHLETE.

The selection of which energy storage type to use for each of the above elements depends upon a number of considerations. These include the power source type (i.e. solar, nuclear, or a supply of reactants such as hydrogen and oxygen), and hardware power level operating requirements and power duration needs (i.e. energy based on mission design). Battery energy storage systems are less complex hardware, at a higher technology readiness level, need to be maintained at a restricted operating temperature range (i.e. to prevent freezing due to the cold lunar surface which can cause permanent damage), and good for lower energy storage levels. Also, when numerous batteries are required to provide an energy level, a level of redundancy due to battery failure can be obtained since the remaining batteries can be operated at higher depth of discharge (although the drawback is the added complexity of managing many batteries). Fuel cell energy storage systems are more complex hardware (e.g. plumbing, valves, controls), at a lower technology readiness level, less sensitive to temperature, and better for higher energy storage levels (i.e. lower mass systems). The fuel cell system design assumes three redundant stacks of cells (one stack can provide the full power level needed), but tanks and reactants are generally not redundant. Thus, for a large system, the redundancy of the fuel cell system may be less than the battery system, although it can be increased by added components.

Both energy storage types can be designed to provide the same maximum discharge power level, however, it is not clear how responsive the fuel cell system is to discharging either rapidly and/or a highly varying rate (electrical vs. fluid/gas flowing). This would suggest a hybrid approach to permit a battery system to handle peak power demands while the fuel cell providing the nominal power. In terms of charging, batteries need to be recharged from an energy source (e.g. either solar arrays, nuclear energy, other batteries or even fuel cell systems). Technology developments have made it possible to recharge lithium batteries much more rapidly; however, this is dependent upon an adequate power source (e.g. large solar arrays). If such large power sources are available, then prolonged recharge is still required (this can be obtained by swapping battery sets and allowing the swapped set to recharge at a lower rate). Fuel cell systems can be recharged either by replenishing the reactants (presumably either generated using electrolysis or some other ISRU process and stored in a central facility) or a dedicated regenerative fuel cell system can be used with an integrated energy source to breakdown water into reactants in a closed loop system. If fuel cells are recharged by connection to separate tanks via lines, then recharge can occur rapidly. However, due to line connections, it is critical that dust-free technology be developed because such dust could damage the fuel cell system (which is normally sealed for infrequent access). If regenerative recharge is used, then recharge may be much slower, even on the order of battery recharge, depending on the power source level. Due to the inefficiency of regenerative fuel cells, the energy source must either be larger or recharged over a longer time than for the battery system.

Even though energy storage and power systems are sub-systems of various elements, the power and support unit (PSU), shown in Fig. 3, is considered the backbone energy storage and power system for the outpost. The PSU incorporates the solar power generation and storage systems, logistics storage, and resource scavenging and transfer equipment. Two different versions of the PSU have been designed: battery and regenerative fuel cell systems both with solar power generation capability. The solar power generation system on the PSU is a $9 \mathrm{~m}$ diameter lightweight deployable solar array derived from the Orion crew exploration vehicle. The PSU is capable of providing power to lunar surface elements during both daylight and eclipse. The capacity of the energy storage and power system is sized based on the driving mission objective of the architecture, in particular the eclipse time expected at the outpost location. 


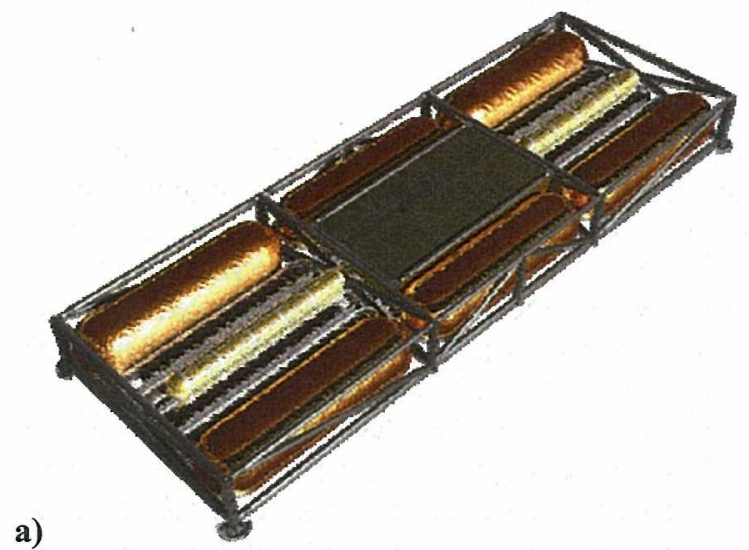

b)

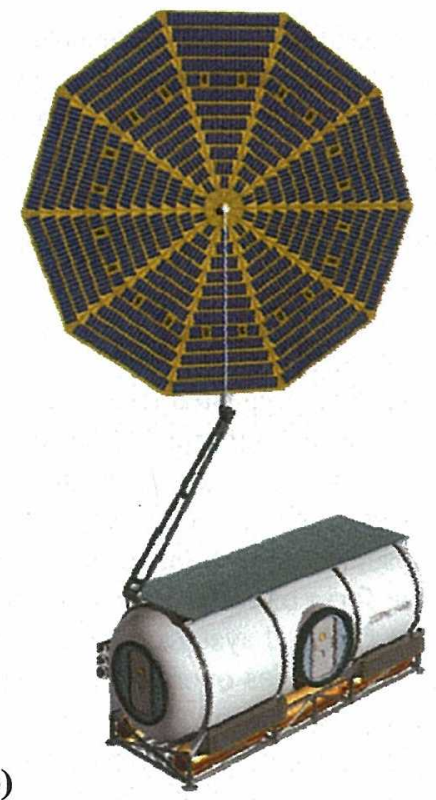

Figure 3. Power and Support Unit. (a) Regenerative Fuel Cell PSU and (b) RFC-PSU integrated with a habitat module and $9 m$ Orion crew exploration vehicle-derived solar array.

\section{Portable Utility Pallet (PUP)}

The Portable Utility Pallet (PUP) is a surface support system primarily designed to augment Lunar Electric Rover (LER) operations (Fig. 4). With the PUP supporting the LER, a crew can operate away from a fixed base for up to 14 days, as opposed to just three days with the LER alone. The PUP provides both storage and transfer hardware for consumable water and oxygen and carries a small pressurized storage module. Additionally, the PUP provides power generation and storage, communications relay, and additional stowage space for samples, spares, tools, and/or science equipment.

The PUP also provides support to the lander and to other systems around the outpost as necessary. Upon arrival of either a crewed or cargo lander, a PUP will connect to that lander to collect (scavenge) all of the water that is produced from the residual propellants. The PUP can also provide power to landers to sustain the ascent module or other payloads. Around the outpost, the PUP can transfer consumables between ISRU plants, habitats, central storage tanks, other PUPs, etc., provide power to surface elements, and provide surface-tosurface and direct-with-Earth (low data rate) communications relay. The PUP carries two sets of power and fluid interfaces that enable a rover or other surface element to connect while the PUP is tending a lander, or to allow the PUP to service two rovers or other surface elements at the same time. Two PUPs can also be connected together via these interfaces.

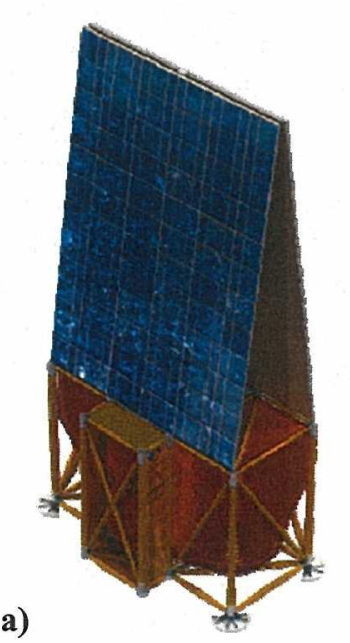

a)

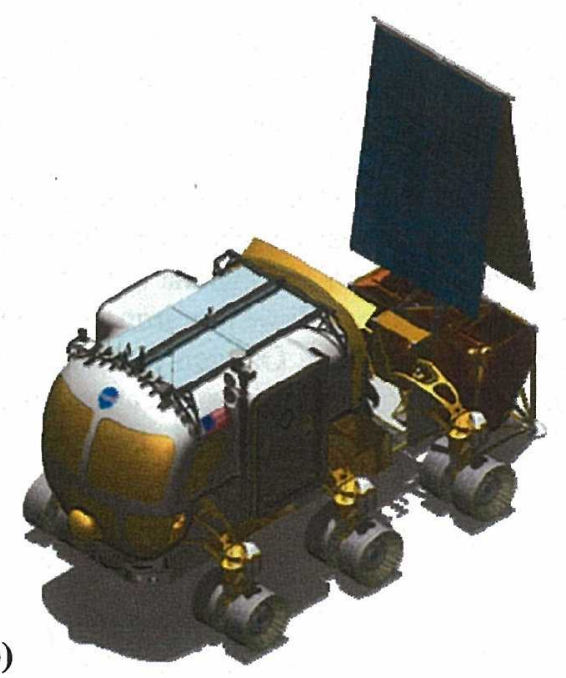

PUP integrated with the LER. 
Baseline PUP designs utilize solar arrays for power generation and carry a quantity of standard batteries with an energy density of $150 \mathrm{~W}-\mathrm{hr} / \mathrm{kg}$ and, at minimum, an equivalent energy storage capacity to the LER. Incorporation of the standard battery facilitates direct battery exchange between PUP and LER in lieu of recharge for contingencies and other operations where time is a factor, and also provides a source of spares should one or more LER batteries fail. However, as the required energy storage capacity increases, the mass of the batteries quickly dominates the total mass of the PUP. The battery mass for the $100 \mathrm{kWh}$ energy storage capacity in the current design comprises nearly $50 \%$ of the overall PUP mass.

\section{Lander Propellant Scavenging}

After a nominal mission, it is suggested the lunar lander will have propellant residual in the tanks equal to $3 \%$ by volume, which is equivalent to $164 \mathrm{~kg}$ and $716 \mathrm{~kg}$ of hydrogen and oxygen, respectively ${ }^{2}$. The propellant residuals are of no use to the lander once its mission is completed. It has been proposed the residual propellant be transferred from the lander to other users, such as for life support for short duration surface missions or for radiation protection water walls for outpost missions. The transfer and storage of these commodities by the surface systems would be most efficient if done in the form of water instead of cryogenic or gaseous states. Hydrogen and oxygen boil-off can be combined into water in a fuel cell system, while at the same time producing power.

Typical hydrogen-oxygen engines operate at an oxidizer:fuel ratio of 5.5:1 while fuel cells run at stoichiometric oxygen:hydrogen mass ratio of 8:1. Because the propellant loading on the descent stage is optimized for propulsion, during propellant scavenging oxygen is depleted before all the hydrogen is used, leaving approximately $80 \mathrm{~kg}$ of the usable hydrogen in the tanks. In average, $440 \mathrm{~kg}$ of water are produced from each lander; however, more water could be produced if in-situ produced oxygen from the Oxygen Production System is combined with the residual hydrogen to produce a total of $1,144 \mathrm{~kg}$ of water per lander mission ${ }^{2}$. The availability of the "excess" water generates a substantial water stockpile, which opens a new approach to optimize the lunar exploration architecture.

\section{Oxygen Production System (OPS)}

The OPS is an In-Situ Resource Utilization (ISRU) process by which lunar regolith is reduced from its oxide form, yielding oxygen. The Hydrogen Reduction system is the baseline system for oxygen production from regolith because it is considered a low risk-mature process. However, other chemical processes are being developed by NASA's ISRU project: Carbothermal Reduction ${ }^{4}$ and Molten Regolith Electrolysis ${ }^{5}$, each with its advantages and disadvantages. Carbothermal Reduction is a more complex process, since it required three steps to produce oxygen (regolith reduction with carbon to form carbon monoxide, reduction of carbon monoxide with hydrogen to form water, and electrolysis of water), but provides an increased oxygen yield up to $28 \%$ by weight. Molten Regolith Electrolysis produces oxygen directly for the molten regolith, yielding $35 \%$ of the oxygen available in the regolith, but long-lasting inert electrodes for this process is a major technological challenge. On the other hand, the hydrogen reduction process is a two-step process. First, iron oxide-bearing minerals are reduced in the presence of hydrogen gas at temperatures higher than $1,073 \mathrm{~K}$ (optimal at or near $1,373 \mathrm{~K}$ ), producing water vapor. Second, the water produced is electrolyzed, generating oxygen and hydrogen. The hydrogen is recycled back to the reactor, making this process closed-loop with no consumables required; the oxygen can either be liquefied for storage, baseline design, or distributed as gaseous oxygen. This system has the capability of producing large quantities of oxygen from lunar regolith, while operating continuously during lunar day. Ilmenite, olivine, pyroxene, and glass are the dominant Fe-bearing phases in lunar soil and all can be reduced in this hydrogen reduction process. Ilmenite however contains the highest concentration of $\mathrm{FeO}$ and has been found in lunar rocks in abundances above $25 \mathrm{wt} \%$ in Mare regions. However, iron concentrations in Highland areas have much less iron content, with typically only $5 \% \mathrm{FeO}$ by weight. Oxygen yields are expected to be no more than $3 \%$ by weight for these soils. However, with the assumption of the outpost location on the lunar pole, where Highland-type regolith is abundant, the conservative oxygen yield is assumed to be $1 \%$ by weight. 
Because the bulk of the energy required to extract oxygen from regolith is used in heating the regolith to operating temperatures, solar concentrators to heat the regolith may be considered as a means to reduce the total ISRU system power requirements. However, current power scenarios have sufficient power available for an allelectric ISRU plant operation, and this is the baseline assumption for the mass, volume, and power estimates.

The current architecture requirement for the ISRU OPS is the production of $1,000 \mathrm{~kg} / \mathrm{yr}$ of oxygen. The ISRU OPS, shown in Fig. 5, assumes (1) electrical power is available from the outpost, (2) a combined maintenance and down-time (during eclipse) of $30 \%$ of Earth-year, (3) two-500 kg/yr OPS are manifested and delivered separately for a combined $1,000 \mathrm{~kg} / \mathrm{yr}$ oxygen production rate, (4) a conservative $1 \%$ by weight oxygen yield, and (5) an regolith excavation unit is available for collection and transportation of regolith.

The excavation unit required to supply the ISRU OPS with the required regolith can be either a small dedicated excavation platform (e.g. Cratos $^{6}$ or Bucket Drum ${ }^{7}$ ), large excavation tools on large mobility platform (e.g. Lance ${ }^{8}$ ), or a combination of both. The current assumption for the

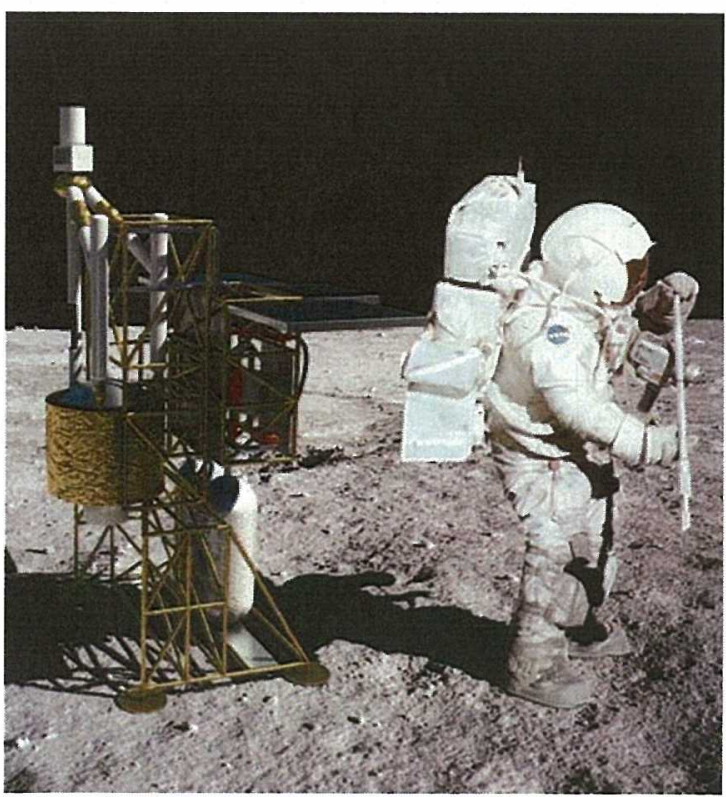

Figure 5. ISRU Oxygen Production System. Hydrogen Reduction System scaled to $500 \mathrm{~kg}-\mathrm{O}_{2} / \mathrm{yr}$. regolith excavation tool is a small excavation attachment on a large mobility platform operating for less than two hours per Earth-day, collecting and delivering $415 \mathrm{~kg} /$ Earth-day of regolith. This excavation requirement is equivalent to excavating a $1 \mathrm{~m}^{2}$ area to a depth of $25 \mathrm{~cm}$, assuming a lunar regolith density ${ }^{9}$ of $1.6 \mathrm{~g} / \mathrm{cm}^{3}$.

\section{Environmental Control and Life Support System (ECLSS)}

The habitat Environmental Control and Life Support System (ECLSS) supports the basic metabolic needs and environmental conditions necessary to support humans in a safe and comfortable environment on the lunar surface. Typical functions allocated to ECLSS include the control of atmospheric pressure and constituency, atmosphere revitalization, water recovery and management, waste management, fire detection and suppression, and emergency response.

As crew-days on the surface accumulate, the commodities needing to be supplied to the crewmembers and the wastes that are generated by crewmembers both increase. To illustrate this, a typical crewmember mass balance, depicting the basic metabolic needs and generated wastes of a representative four-person crew over the course of a year, is shown below in Fig. 6. Of special note is the fact that through normal metabolic conversion of food, such a crew releases about $480 \mathrm{~kg}$ more water in wastes than they consume over the course of a year.

To reduce the yearly mass needing to be resupplied and disposed of, regenerative life support processes can be utilized. A wide variety of approaches can be considered for a regenerative life support architecture. Typically, the degree that oxygen and water is recovered from metabolic and habitation wastes represents a trade-off of consumables and equipment resupply versus system complexity and risk. One such possible approach is depicted in Fig. 7.

The depicted ECLSS architecture includes a combination of flight qualified technologies enhanced beyond current heritage capabilities and new technologies never previously developed for spaceflight application. Envisioned enhancements to heritage technologies include the generation of oxygen at high pressures to facilitate low-volume storage, robust and low power carbon dioxide removal, and fecal and waste management techniques adapted for volume reduction and long duration stabilization, and water recovery techniques applicable to a broader range of waste water types. New technologies target increasing the overall amount of water recoverable through processing of concentrated waste brines, drying of fecal and trash wastes, and conversion of solid waste residues to recoverable carbon dioxide and water by-products. Laundry capability reduces the amount of clothing and linens needed to be supplied for the mission. By implementing such a mix of technologies, the amount of mass needing to be supplied for a year-long, four-person mission can be reduced by more than $4,000 \mathrm{~kg}$. Furthermore, excess water, oxygen, and hydrogen can be made available to support other mission needs such as extravehicular activities (EVA), fuel cell reactants, and/or radiation protection. 


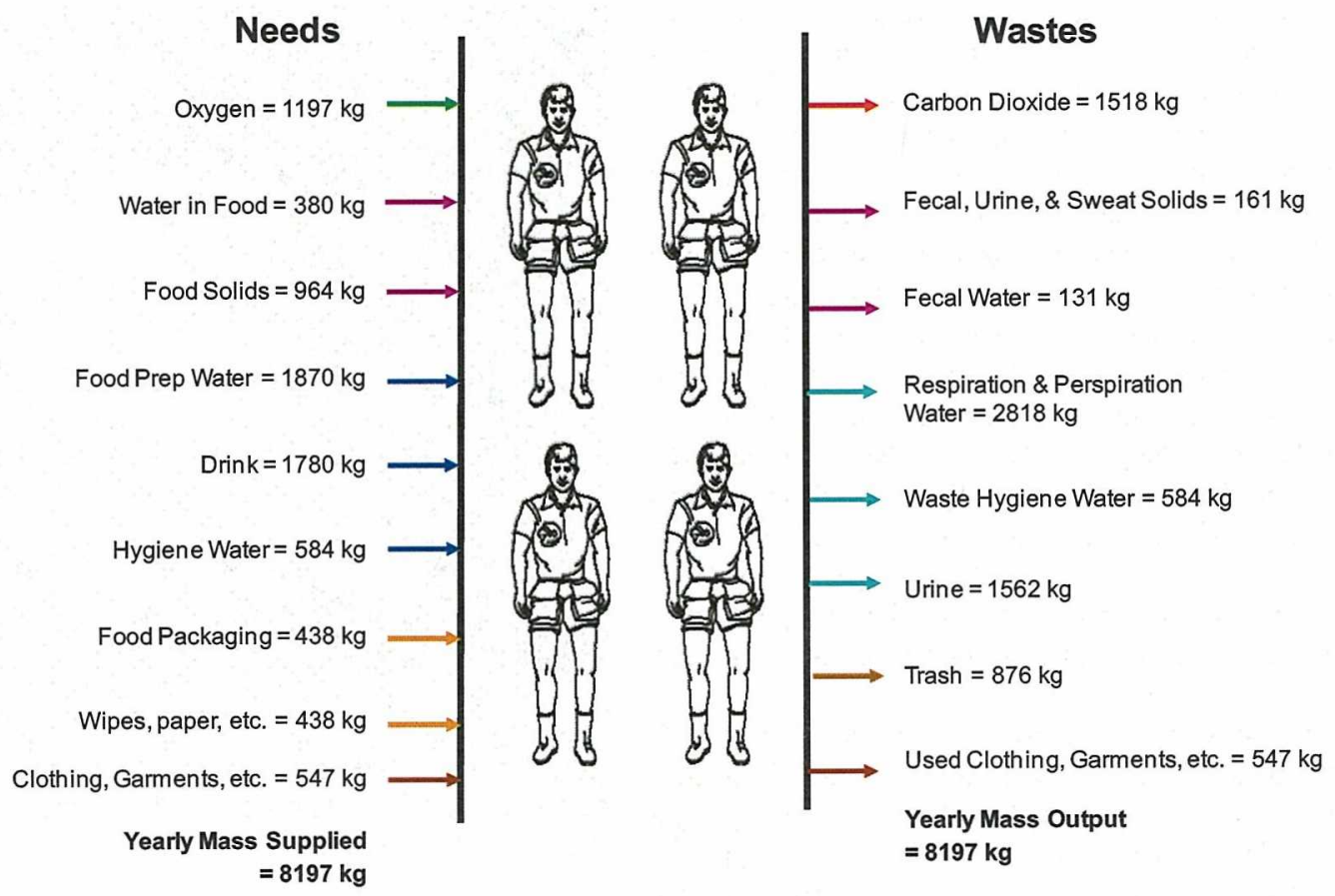

Figure 6. ECLSS assumptions. Representative Crewmember Metabolic Needs \& Generated Wastes over One Year

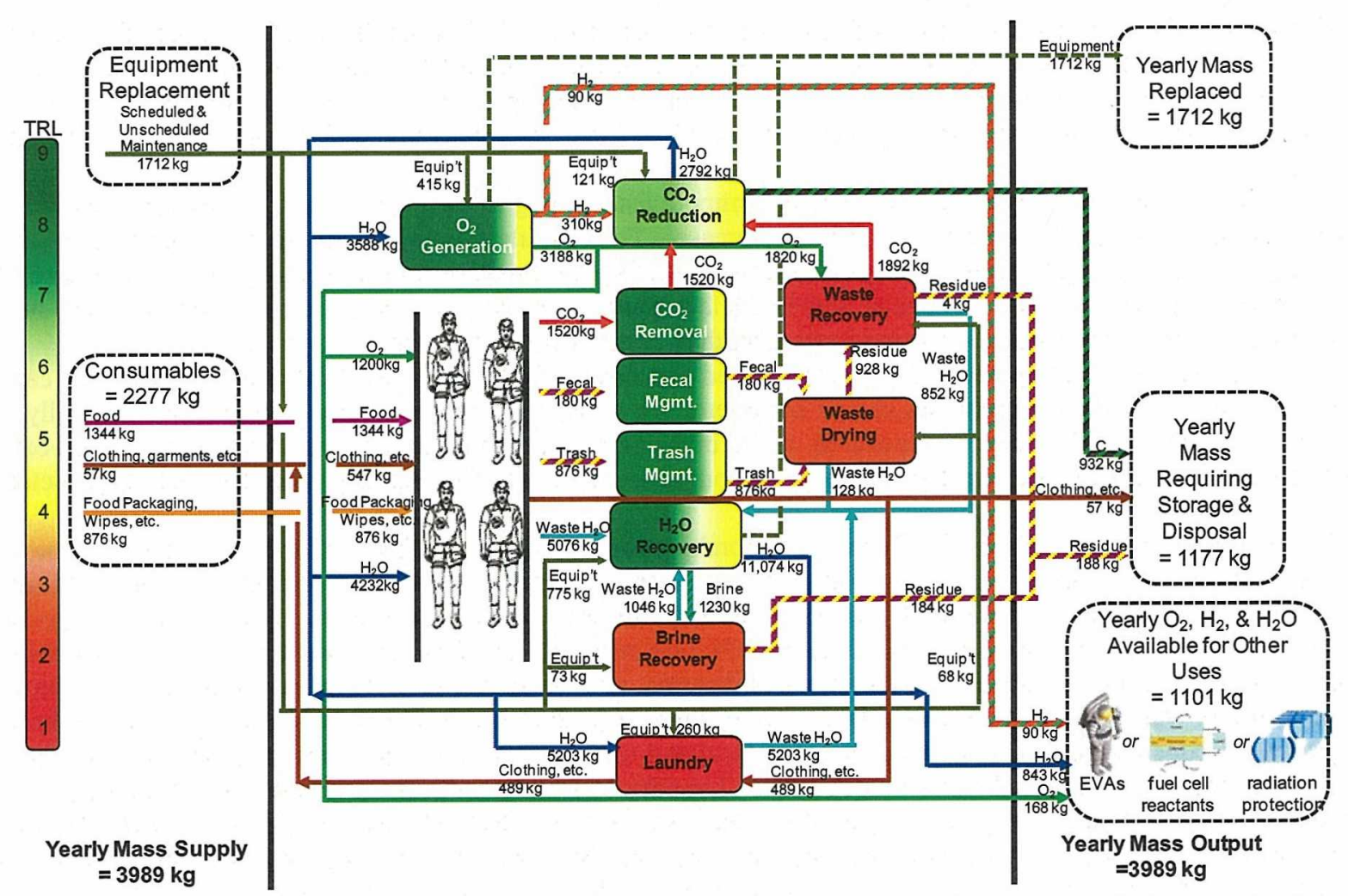

Figure 7. ECLSS Architecture. Representative regenerative ECLSS architecture, including Technology Readiness Level of each sub-system. 


\section{Lunar Campaign Scenario}

The water accumulation analysis described in this paper applies to a specific scenario analysis, known as Scenario 12, specifically Scenario 12.0.2 variant. This scenario campaign was conceptualized based on integrating some of the best attributes from previous scenario campaign analyses. The scenarios integrated into Scenario $12 \mathrm{kept}$ as their major objective to: (1) optimize exploration, (2) optimize outpost power by using a Fission Surface Power System, and (3) optimize the mobility with mobile assets deployed early in the campaign. The combination of these scenarios morphed into what was considered a matured scenario, where a detailed analysis was performed on the "Con-Ops" (concept of operation) as an addition to the required standard products developed for each of the scenario campaigns. One of the standard products required is the development of a flight manifest describing each mission, which is shown in Fig. 8.

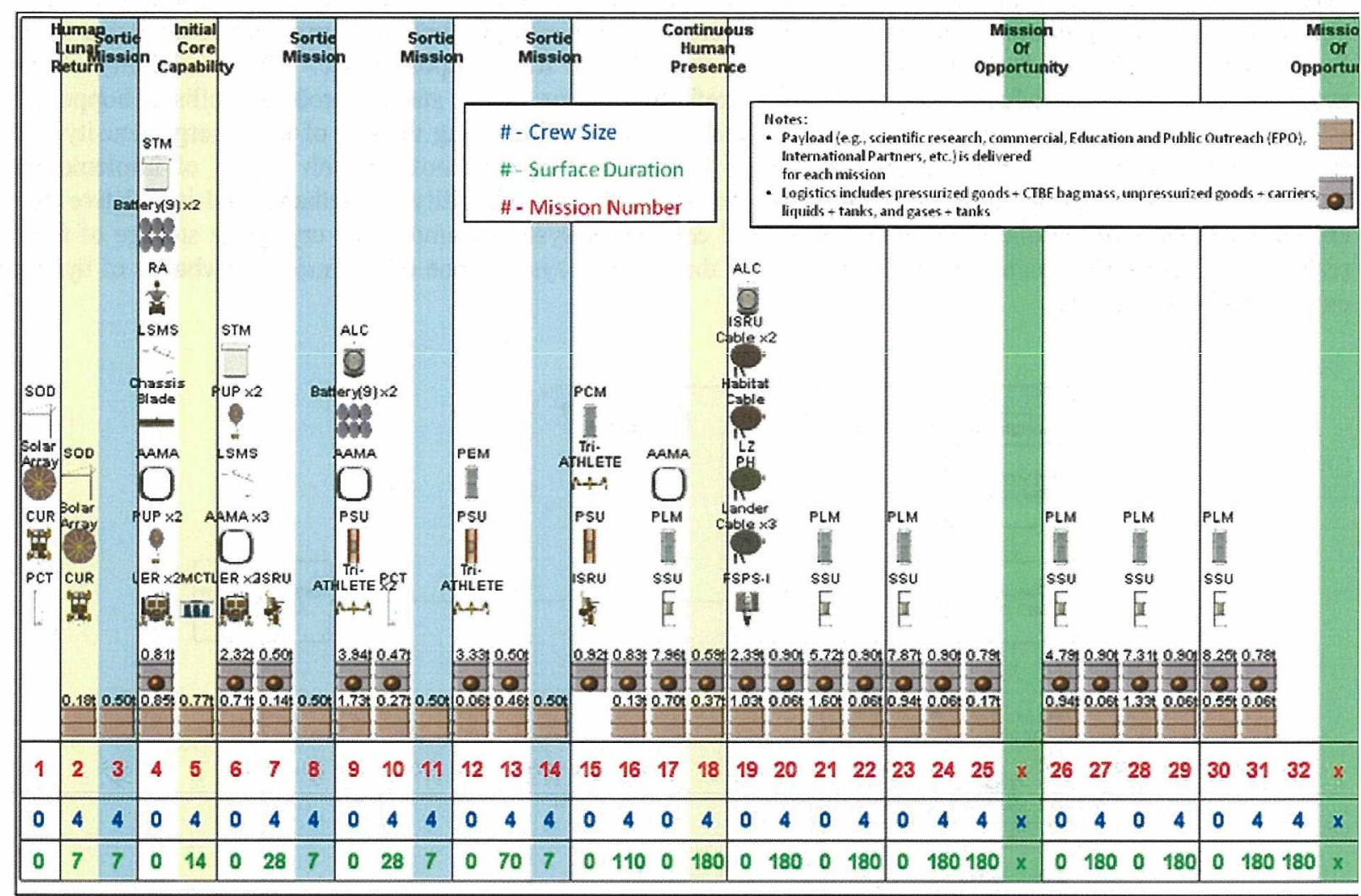

Figure 8. Scenario 12 manifest. Manifest includes: Small Offloading Device (SOD), Constellation Unpressurized Rover (CUR), Portable Communication Terminal (PCT), Lunar Electric Rover (LER), Portable Utility Pallet (PUP), Active-Active Mating Adapter (AAMA), Lunar Surface Manipulator System (LSMS), Robotic Assistant (RA), Suitport Transfer Module (STM), ISRU OPS (ISRU), Power \& Support Unit (PSU), Airlockderived Logistic Module (ACL), Pressurized Excursion Module (PEM), Pressurized Crew Module (PCM), Structural Support Unit (SSU), Pressurized Logistic Module (PLM), and Fission Surface Power System (FSPS).

The detailed Con-Ops analysis included a detail analysis of the logistics, including the usage of consumables. This detail analysis was performed using the Campaign Manifest Analysis Tool (CMAT). The CMAT requires a campaign definition, which consists, primarily, of the parameters necessary to describe the set of missions that will constitute the campaign. Such parameters are the number of crew delivered, the length of crewed surface duration, the delivery capacity of the transportation system, and the payloads delivered. Once the campaign has been defined, the logistics requirements are calculated for each mission based on the mission parameters, the capabilities of the manifested elements, and a set of assumptions about crew consumption, Extra-Vehicular Activity (EVA), logistics, science requirements, and In-Situ Resource Utilization (ISRU) ${ }^{10}$. The required logistics are then loaded onto each mission within carriers for delivery prior to their date of use. Any cases in which the logistics could not be loaded due to limited capacity are flagged for further attention by the analyst. Campaign definition, logistics requirements 
calculation, and logistics loading are iteratively performed until the campaign is performing satisfactorily ${ }^{11}$. The CMAT closure process is graphically represented in Fig. 9. The analysis tool has also an additional (optional) iteration process for closing crew time availability, which is a required when analyzing exploration and science activities.

\section{Analysis and Discussion}

The analysis performed on Scenario 12 up to this point has only included a conservative approach to a sustainable lunar outpost development. However, as the scenarios mature we seek to implement new revolutionary approaches and ideas to increase the self-sufficiency of the outpost, while increasing exploration and science objectives. These new ideas, which will be discussed further in the sections to follow, are as a result of one major implementation: maximize the water production and recuperation. Implementing this approach will open a new architecture and a new expansion of exploration possibilities. This includes the in-situ production of propellants achieved (such as fuel, $\mathrm{CH}_{4}$ ) by combining hydrogen from the water with carbon from outpost waste. The availability of in-situ produced propellants introduces the possibility of refueling Altair ascent stage or robotic ballistic hoppers. The availability of water at the outpost will open the trade space by minimizing the use of low energy density battery systems while maximizing the use of high energy density fuel cell technology with a goal of implementing a regenerative fuel cell power system architecture. In addition, the availability of methane, and its relative ease of cryogenic storage, offers one more option for a fuel cell power system, namely, the cryogenic storage of fuel cell reagents $\left(\mathrm{LCH}_{4}-\mathrm{LOx}\right)$, which reduces the volume of the fuel cell system, one of the major drawbacks of hydrogenoxygen fuel cell systems.

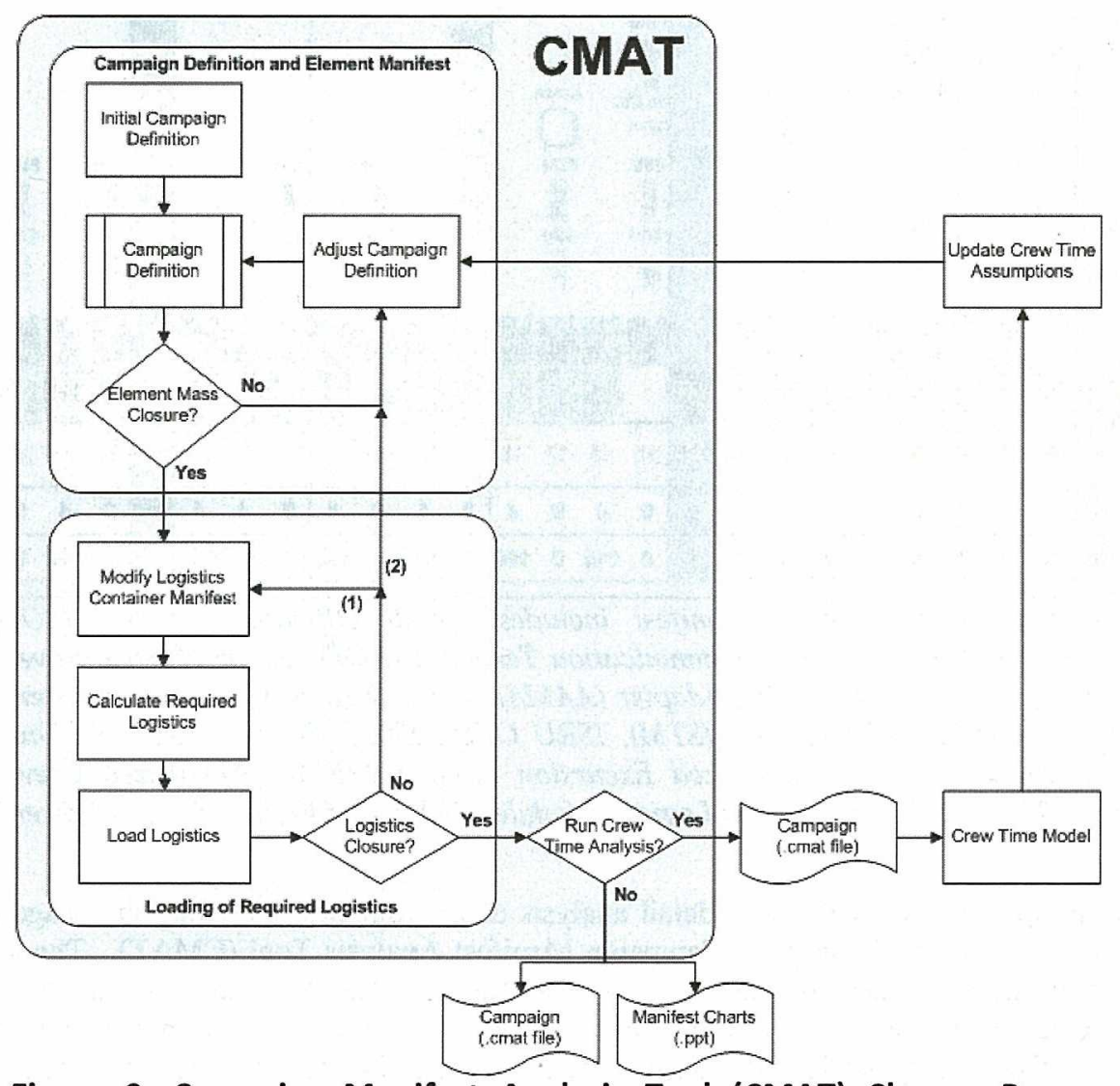

Figure 9. Campaign Manifest Analysis Tool (CMAT) Closure Process. Process flow diagram for the CMAT used to perform detailed analyses of LSS scenarios. 


\section{A. Water Production and Accumulation}

As it has been discussed the ability to maximize the production of water and to close the water loop on the outpost can bring innovative approaches to perform science and exploration missions. In the baselined approach for Scenario 12, the significant contributions to the water stockpile at the outpost depend largely on the Environment Control and Life Support System (ECLSS) settings and the scavenging of the propellant residuals from the lander descent stage. The ECLSS settings of the habitation elements include water recovery at a rate of $93.5 \%$ from wastewater, $50 \%$ of water recovered from solids drying, $99 \%$ recovered from brine, and propellant scavenging equipment providing $440 \mathrm{~kg}$ of additional water per descent Altair lander. CMAT analysis of the baseline scenario yields a water stockpile of approximately $4,000 \mathrm{~kg}$ after the initial outpost build up and habitation (i.e. first 10 years of lunar presence). However, in an enhanced-scenario option, assuming a conservative water production from propellant scavenging of $1,000 \mathrm{~kg}$ per lander mission, the CMAT analysis estimates a water stockpile of near 16,500 $\mathrm{kg}$ after the same initial build up and habitation phase. Figure 10 shows the water accumulation profile given by the CMAT analysis of the baselined Scenario $12(440 \mathrm{~kg}$ water from propellant scavenging) versus the enhanced version of the scenario (assuming a conservative $1,000 \mathrm{~kg}$ of water from propellant scavenging).

The water profile achieved in the enhanced scenario is possible only by the additional $560 \mathrm{~kg}$ of water produced during propellant scavenging of Altair's descent stage. As discussed before, the baselined scenario assumes propellant scavenging up to the point where oxygen is depleted due to the propellant loading to support propulsion at an oxidizer:fuel ratio of 5.5:1, whereas fuel cell operations require a ratio of $8: 1$. Once Altair's descent stage is depleted of oxygen, approximately $60 \mathrm{~kg}$ to $80 \mathrm{~kg}$ of hydrogen are estimated to remain in the propellant tanks. If this hydrogen residual is combined with oxygen produced by the OPS an additional $540 \mathrm{~kg}$ to $720 \mathrm{~kg}$ of water could be produced.

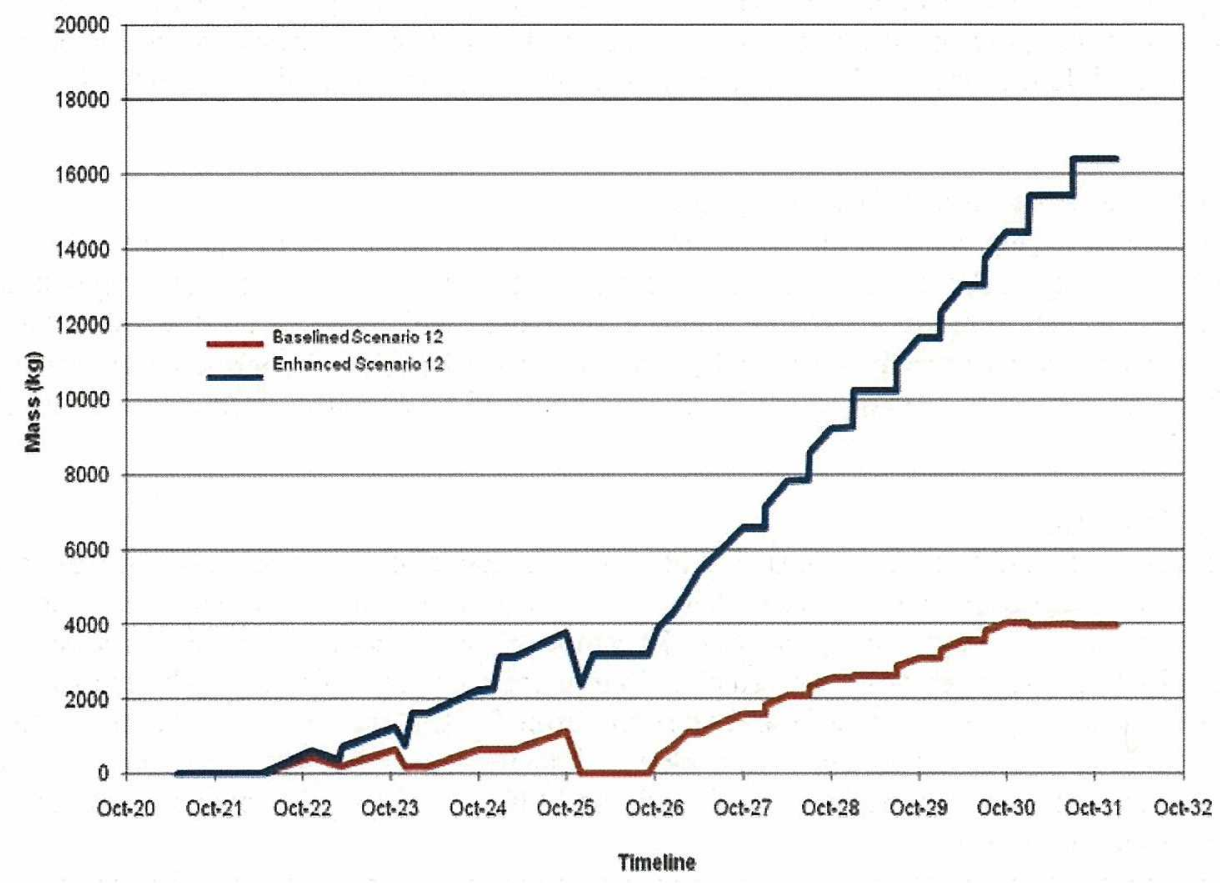

Figure 10. Water accumulation profile. Profile of water accumulation over the first 10yrs of operation of the outpost. Baseline scenario assumes $440 \mathrm{~kg}$ of water are recuperated from propellant scavenging, while the enhanced scenario assumes a conservative 1,000 kg of water, assuming ISRU oxygen is integrated into the propellant scavenging process.

The current requirement imposed onto the ISRU OPS is the production of $1,000 \mathrm{~kg}$ of oxygen per year, which does not take into account the increased oxygen production required to support an architecture based in the enhanced scenario version. However, the additional production requirement for oxygen will increase by an approximately $1,000 \mathrm{~kg} / \mathrm{yr}$, that is $1,000 \mathrm{~kg} / \mathrm{yr}$ to support Extra-Vehicular Activities (EVA) and ECLSS (already included in the 
baselined Scenario 12) and 1,000 kg/yr to support two lander propellant scavenging process per year. Although, this requirement will increase to $3,000 \mathrm{~kg} / \mathrm{yr}$ once the campaign begins the full operation phase of the outpost (missions 15+, per Fig. 8), where four Altair missions per year are manifested. Assuming the same $500 \mathrm{~kg} / \mathrm{yr} \mathrm{scale} \mathrm{OPS}$ described previously and an early deployment of OPS, a total of six OPS will be required in order to support an enhance scenario. Given the economy of scale analysis previously perform on the ISRU OPS using the ISRU modeling tool reported in Ref. 12, it would be more efficient to have fewer OPS with higher production rates. Hence, the smarter lower risk approach would be to have a series of OPS that progressively increase in capability as the system mature. Such OPS deployment would follow this strategy, assuming the same flight sequence shown in Fig. 8:

- Deploy a $500 \mathrm{~kg} / \mathrm{yr}$ scale OPS on mission 2. This OPS could be considered as a test-flight unit to help mature the technology. Because EVA and ECLSS oxygen requirement is not needed until extended human presence, the single $500 \mathrm{~kg} / \mathrm{yr}$ OPS could support both propellant scavenging and reduced outpost needs.

- Deploy a $1,000 \mathrm{~kg} / \mathrm{yr}$ OPS in mission 7. This OPS unit would have been scaled-up and design with improvements based on the performance of the test-flight unit deployed in mission 2. At this point, the outpost has the capability of producing $1,500 \mathrm{~kg} / \mathrm{yr}$ of oxygen, while the outpost's needs are less than $2,000 \mathrm{~kg} / \mathrm{yr}$ due to the short duration human presence (i.e. 28 days per year).

- Deploy a $2,000 \mathrm{~kg} / \mathrm{yr}$ OPS in mission 15 . This OPS unit would bring the combined oxygen production capability to the full outpost need, and provides an extra $500 \mathrm{~kg} / \mathrm{yr}$ for contingency.

This evolution approach to the OPS design reduces the risk of each subsequent OPS design by improving on the design of the previous system, making sure the OPS is capable of providing the required oxygen in order to support the increased water production from propellant scavenging. As the outpost grows and becomes more complex, the sustainability and self-dependency of the outpost will rely heavily on the reliability of the OPS.

\section{B. In-situ Fuel Production and Ballistic Hoppers}

The availability of excess water in the lunar outpost opens yet another set of innovative approaches to increase the exploration capability of the lunar scenarios. These new approaches are: (1) use of oxygen and hydrogen (from electrolyzed excess water) to produce storable fuel (i.e. methane), which can be used as propellant when combined with in-situ produced oxygen from the OPS, and (2) introduction of ballistic hoppers, which can be used to perform round-trips from the outpost to sites of scientific interest powered by chemical propulsion burning in-situ produced propellants.

\section{In-situ Fuel Production}

A long-standing sustainable lunar outpost should be able to manufacture useful products with resources available to make use of every gram of mass launched from Earth. As presented in this paper, the scenario 12 campaign yields an accumulation of water during the first 10 years of the outpost. This excess water could be used as propellant for a hydrogen-oxygen powered vehicle. One major challenge of using hydrogen as fuel is the very low temperature (i.e. $20 \mathrm{~K}$ ) required to liquefy and store the propellant. Hence, at a lunar outpost, the production of a storable fuel will be required. Methane, with a modest liquefaction and storage temperature of $112 \mathrm{~K}$, is a good candidate fuel as methane-burning engines provides reasonable propulsion performance, and the outpost has all the resources required to produce it.

The Moon contains little or no carbon; however, enough carbon is generated by the presence of humans at the lunar outpost to produce methane at a significant rate. One source of carbon is the carbon dioxide exhaled by the astronauts, which is currently captured and processed by ECLSS to recycle oxygen. Carbon dioxide is easily reduced in the presence of hydrogen producing methane and water in a well-known exothermic catalytic process called Sabatier process,

$$
\mathrm{CO}_{2}+4 \mathrm{H}_{2} \rightarrow \mathrm{CH}_{4}+2 \mathrm{H}_{2} \mathrm{O} \text {. }
$$

Following the Sabatier process, the water is electrolyzed, producing hydrogen and oxygen gas. The hydrogen is recycled back to continue the reduction of carbon dioxide and the oxygen is pumps back into the habitat.

Outpost waste, in the form of human waste and trash, is also a source of carbon that can be processed into methane. Waste management at the outpost is required in order to protect the lunar environment and maximize the 
use of pressurized habitats. The current strategy for waste management on the International Space Station is to pack the waste into logistic modules, and bring it back to Earth. On a Lunar mission, transporting the waste from the surface to orbit and back to Earth is not feasible considering a waste generation rate of $0.3 \mathrm{~kg} / \mathrm{day}$ waste per crew member ${ }^{13}$. Furthermore, the storage of waste inside pressurized habitats or logistic volumes can create health hazards for the astronauts as well as taking up valuable habitable volume. There are several techniques to convert waste into fuels: (1) thermally degrading waste in the presence of oxygen producing carbon oxides, which are further reacted into fuels, (2) direct fuel production via pyrolysis, and (3) biological process ${ }^{14}$.

Thermal oxidation and pyrolysis are energy intense chemical processes; however, they offer the ability to be automated, ruggedized and have similarities to oxygen production processes intended for lunar applications. The biological process refers to anaerobic digestion; hydrolysis, acetogenesis, and methanogenesis. Given the current architecture, the biological processing has a limited portion of the waste stream it can break down since the plastics are not biodegradable. However, if the plastics used during the missions were changed to biodegradable plastics, the entire waste stream could be utilized by the bacterial colonies. Biological processes are lower in energy but require environmental controls to keep the bacterial colonies in balance.

The outpost trash, mainly food packaging, is made from various variations of polyethylene $\left(\mathrm{C}_{2} \mathrm{H}_{4}\right)$ polymer. The thermal oxidation of polyethylene to form carbon oxides follows the chemical equations:

$$
\begin{aligned}
& \left(\mathrm{C}_{2} \mathrm{H}_{4}\right)_{\mathrm{n}}+2 \mathrm{O}_{2} \rightarrow 2 \mathrm{CO}+2 \mathrm{H}_{2} \mathrm{O} \\
& \left(\mathrm{C}_{2} \mathrm{H}_{4}\right)_{\mathrm{n}}+3 \mathrm{O}_{2} \rightarrow 2 \mathrm{CO}_{2}+2 \mathrm{H}_{2} \mathrm{O} .
\end{aligned}
$$

These carbon oxides would be further reacted with hydrogen following Eq. (1), and its variation for CO reduction to produce methane and water. Dry biological human waste would follow a similar process of thermal oxidation followed by carbon oxides reduction to produce methane.

Table I summarizes the potential methane production from metabolic $\mathrm{CO}_{2}$ (ECLSS) and outpost waste (human and trash). The outpost trash processing would require $721 \mathrm{~kg} / \mathrm{yr}$ of oxygen for the thermal oxidation step and 90 $\mathrm{kg} / \mathrm{yr}$ of hydrogen for the carbon oxides reduction yielding $361 \mathrm{~kg} / \mathrm{yr}$ of methane. ECLSS is capable of producing $531 \mathrm{~kg} / \mathrm{yr}$ of methane, while requiring $133 \mathrm{~kg} / \mathrm{yr}$ of hydrogen. The hydrogen $(223 \mathrm{~kg} / \mathrm{yr})$ required to produce methane from ECLSS and water processing is equivalent to $2,000 \mathrm{~kg} / \mathrm{yr}$ of water, which is the same level of water assumed to be produced from propellant scavenging in a year (assuming at least two Altair missions to the outpost per year). However, because the carbon mass balance on these estimates requires a continuous human presence at the outpost (i.e. continuous generation of carbon source), this full methane production capability would only become available after mission 17 (Fig. 8). The integrated full-scale fuel production system would use a scaled-up version of the current ECLSS $\mathrm{CO}_{2}$ reduction system to include the reduction of carbon oxides from the waste processing. Therefore, this option only introduces one new element, reducing developmental and launch costs for these elements.

Table I also includes the propellant requirement to fuel an ascent stage of the Lunar Surface Access Module (LSAM) described in NASA's ESAS ${ }^{15}$ report, which baselined a $\mathrm{LOx}-\mathrm{LCH}_{4}$ propulsion system on the ascent stage. The ESAS report estimated a propellant requirement for the ascent stage of approximately $4,000 \mathrm{~kg}$ of propellant, which at a $3.4 \mathrm{O}_{2}: \mathrm{CH}_{4}$ ratio results in $3,090 \mathrm{~kg}$ of $\mathrm{O}_{2}$ and $910 \mathrm{~kg}$ of $\mathrm{CH}_{4}$. If we assume a similar propellant requirement exist in the ascent stage of Altair (for the sake of comparison to the current architecture) and we launch Altair from Earth with an empty ascent stage, the capabilities of in-situ propellant (fuel and oxidizer) production and ascent stage fueling would make available $4,000 \mathrm{~kg}$ of payload in one manned Altair mission per year. Even if launching an empty ascent stage provides a significant mass increase capability to the manned mission that could be used for science or other surface system payloads, astronauts and mission managers do not accept the risk of eliminating the "abort-to-orbit" contingency plan in the case of descent stage malfunction or landing concern.

There is one more option to help reduce the mass of propellant on the ascent stage launched from Earth, while maintaining an "abort-to-orbit" capability (i.e. launching the ascent stage with sufficient propellant to perform an "abort-to-orbit"). Once on the lunar surface, the ascent stage can be fueled to the level required for a nominal launch. Further analysis for this ascent stage propellant at Earth-launch scenario is required, since a minimum altitude will be required in order to estimate the propellant required for the abort-to-orbit burn. At a minimum, the availability of ascent stage propellant on the lunar surface provides risk reduction to the ascent stage propellant fluid management. In the case where cryogenic fluid management malfunctions and propellant is lost at an elevated rate, the in-situ produced propellants would provide refueling capability to replenish the propellant lost. 
Table I. In-Situ Fuel Production Summary. Mass of resources required to produce methane, and (*) the amount of propellant required to re-fuel Altair's ascent stage. (**) $\mathrm{O}_{2}$ required to support waste processing by oxidation.

\begin{tabular}{|c|c|c|c|c|c|c|}
\hline Source & $\begin{array}{c}\mathrm{H}_{2} \\
\text { required } \\
\text { (kg/yr) }\end{array}$ & $\begin{array}{c}\mathrm{CH}_{4} \text { from } \\
\text { Waste } \\
\text { (kg/yr) } \\
\end{array}$ & $\begin{array}{c}\mathrm{CH}_{4} \text { from } \\
\text { Metabolic } \\
\mathrm{CO}_{2}(\mathrm{~kg} / \mathrm{yr})\end{array}$ & $\begin{array}{c}\text { Total }^{\mathrm{CH}_{4}} \\
\text { produced } \\
\text { (kg/yr) }\end{array}$ & $\begin{array}{c}\mathrm{O}_{2} \\
\text { required* } \\
\text { (kg/refuel) }\end{array}$ & $\begin{array}{c}\mathrm{CH}_{4} \\
\text { required } \\
\text { (kg/refuel) }\end{array}$ \\
\hline Waste Processing & 90 & 361 & -- & \multirow{3}{*}{892} & \multirow{3}{*}{3090} & \multirow{3}{*}{910} \\
\hline ECLSS & 133 & -- & 531 & & & \\
\hline ISRU $\mathrm{O}_{2}(\mathrm{~kg} / \mathrm{yr})^{* *}$ & -- & 721 & -- & & & \\
\hline
\end{tabular}

A conservative mission risk management most likely would reject the use of manned mission to demonstrate new technology and capabilities, as it is the case of using in-situ produced propellant. However, robotic missions could definitely provide an excellent testbed for the demonstration of such capability, which a lunar outpost, as a possible stepping stone to enable human Mars mission, should demonstrate (i.e. the capability of propellant production, storage, transfer, and usage). These missions would consider the use of ballistic robotic hoppers to perform round-trip scientific and exploratory missions from the lunar outpost. This approach is discussed in details in the next section.

\section{Ballistic Hoppers}

Lunar human exploration architectures are typically limited in exploration range because of mass budget limits on consumables, energy storage for surface vehicles, and mission duration. In order to significantly increase the exploration range, augmenting the science accomplished, the architecture would require the use of hoppers (i.e. ballistic hoppers). These rocket-powered hoppers would carry a suite of automated science instruments (i.e. robotic hopper) or a team of astronauts with science instruments (i.e. manned hopper) to destinations far away from the outpost that would be impractical to reach by a surface mobility platform. A robotic science hopper could introduce a heavy science campaign by performing a series of roundtrips from the outpost to various site of scientific interest. In scenarios where surface mobility is preferred, consumable hoppers could be deployed in advance of the manned excursion to provide a consumable depot away from the outpost. These consumable hoppers could be deployed at the maximum distance achievable by the mobility platform, doubling the exploration range of the excursion and providing a "safe-haven" in case problems arise during the expedition.

The detailed design of a hopper was outside the scope of this study; however, general assumptions were taken in order to evaluate the applicability of using hoppers in a lunar scenario where various levels of in-situ produced propellant were available. Given the technical challenges of liquefying and storing hydrogen, these hoppers would be propelled by liquid methane-liquid oxygen $\left(\mathrm{LCH}_{4}-\mathrm{LOx}\right)$ engine, with a representative generic engine capable of producing an Isp of 350 seconds. The delta-V $(\Delta \mathrm{V})$ required for the sub-orbital hops to any given change in latitude (or hop distance) is estimated using Copernicus ${ }^{16}$. Logarithmic and polynomial regressions were used to model and extrapolate a fit to the data obtained from Copernicus resulting in Eq. (4)

$$
\Delta \mathrm{V}=0.725 * \ln (\text { change in latitude })-0.262 \text {, }
$$

where change in latitude is in degree and $\Delta V$ is in $\mathrm{km} / \mathrm{s}$. Figure 11 shows the idealized delta- $V$ requirement for suborbital hops on the Moon derived from Eq. (4). The required propellant mass to perform the delta-V per desired change in latitude was determined using Eq. (5), which was derived from the rocket equation.

$$
\text { Propellant Mass }=\left(\mathrm{e}^{\left(\Delta V /\left(s p{ }^{*} g\right)\right)}-1\right) * d r y \text { mass }
$$

where propellant mass is in kilogram, $\Delta V$ in $\mathrm{m} / \mathrm{s}, I s p$ in $\mathrm{s}, g$ in $\mathrm{m} / \mathrm{s}^{2}$, and $d r y$ mass in kilograms. Equation (5) provides an estimate of the propellant required to perform a one-way hop for a given hopper dry mass. The dry mass values would need to include all elements of the hopper and its payload other than the propellant, for example: hopper structure, astronauts, science payload, instruments, any required systems, and propellant tanks. Figure 12 shows the mass of propellant required for varying hopper sizes. 
In order to size the hopper, a detailed analysis of the mission's objectives and availability of the propellant will be required. An analysis of the specific mission objectives would investigate the goals and objectives of: (1) science, which will provide inputs on hop distance based of sites of interest, payload mass requirements, and mission profile, (2) exploration, which provides information on the requirements for a consumable depot hopper or an exploration scout hopper. One would expect that for a science mission long distance hops with relative small payload mass would be required, suggesting a small robotic hopper in the $500 \mathrm{~kg}$ to $1,000 \mathrm{~kg}$ size class. On the other hand, exploration missions would require a larger payload mass in shorter hop distances, suggesting a larger class hopper. However, an exploration scout hopper would be small with relative short hop distance. Selecting the best hopper size to meet all mission requirements is a complex task outside the scope of this study and not discussed in this paper.

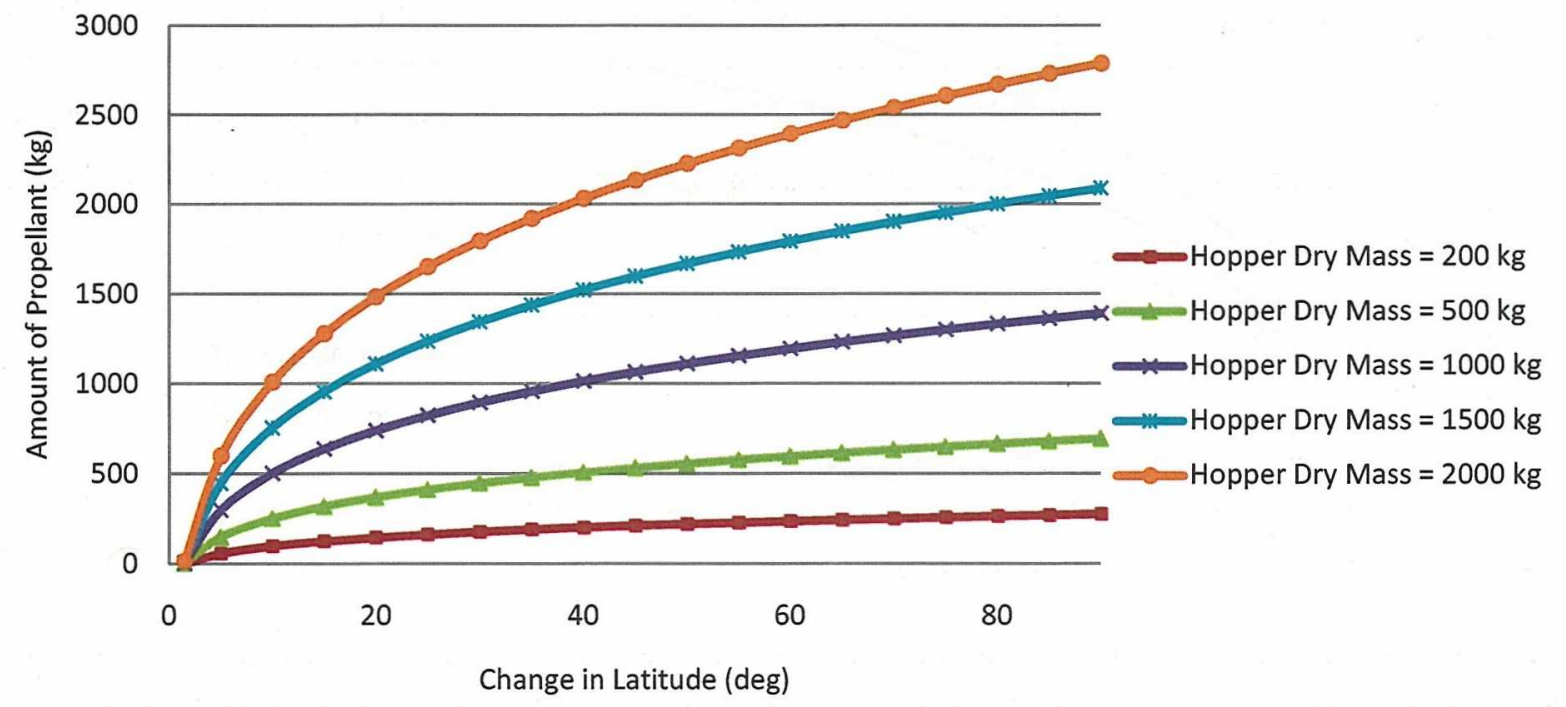

Figure 12. Propellant requirement vs. change in latitude for a one-way hop. The amount of propellant required for an ideal hop for various dry mass as described by Eq. (5). A $1^{\circ}$ latitude change represents $30 \mathrm{~km}$ of lunar surface, assuming a circumference of 10,864 kilometers. 


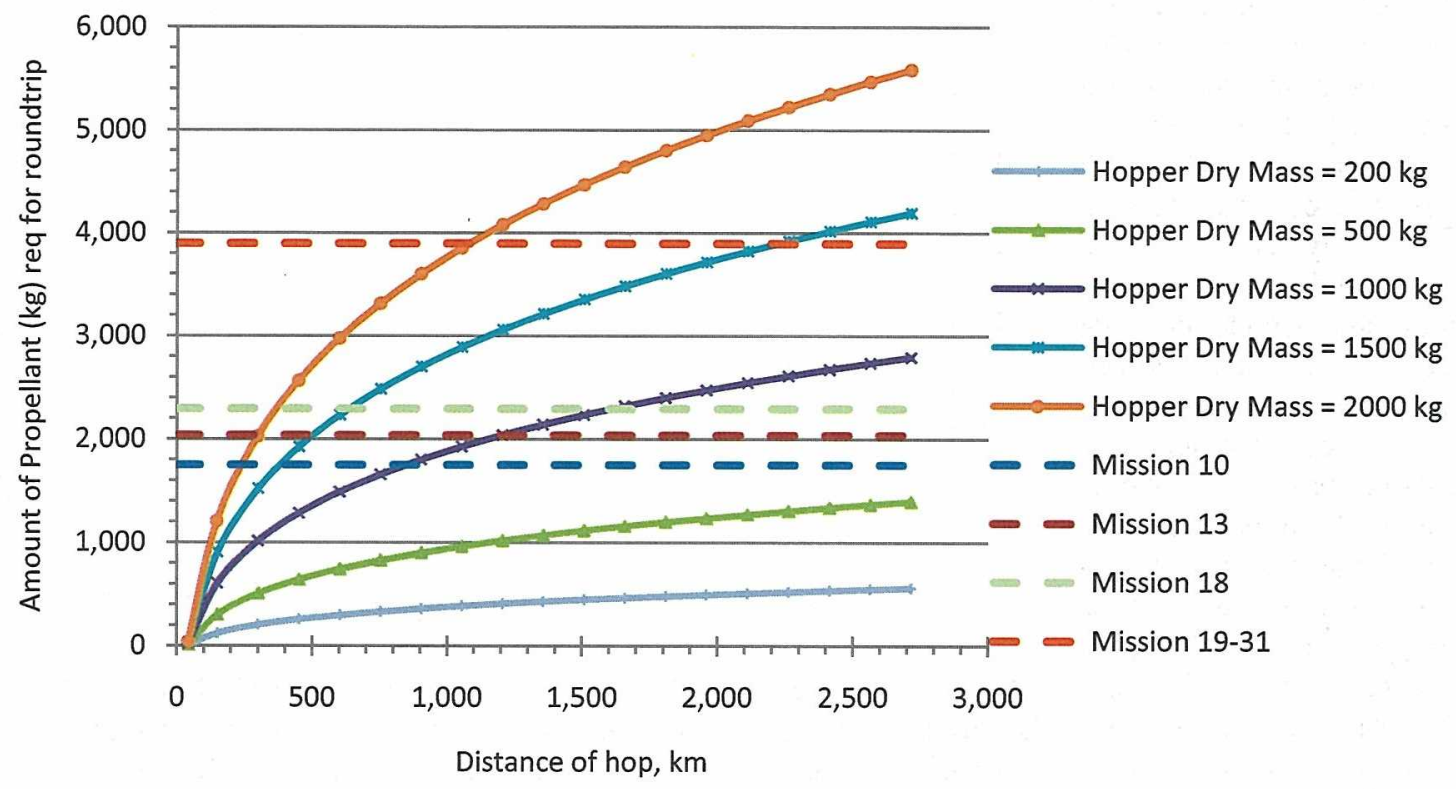

a)

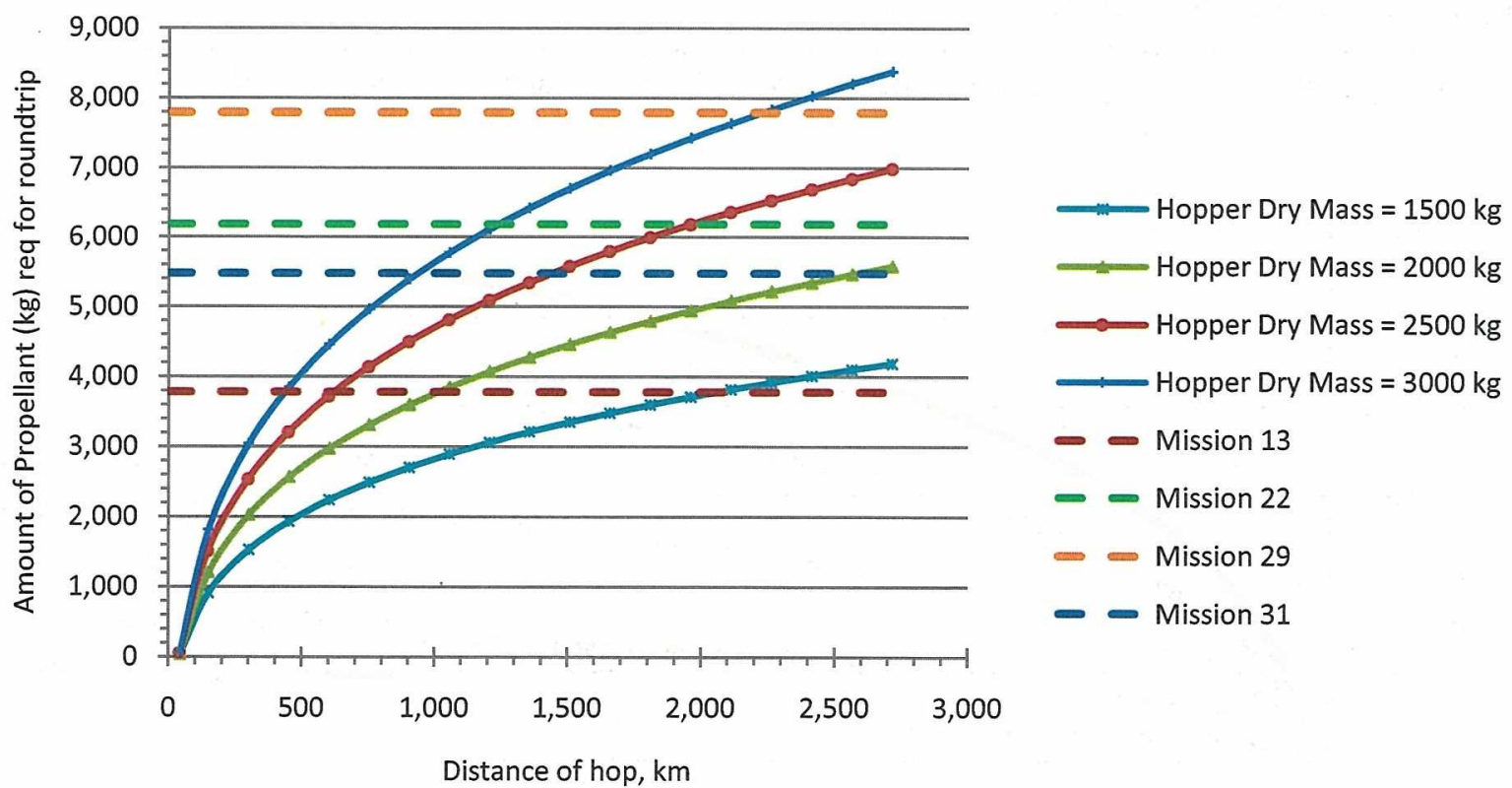

b)

Figure 13. Roundtrip propellant requirement vs. distance of hop. The amount of propellant required for an ideal roundtrip hop for various dry mass hopper as described by Eq. (5). The horizontal lines are the mass of propellant accumulated by the end of the specified mission. a) is the mass of propellant accumulated in small mission increments (i.e. one Erath-year), while b) assumes larger mission increment (i.e. two Earth-years). A $1^{\circ}$ latitude change represents $30 \mathrm{~km}$ of lunar surface, assuming a circumference of 10,864 kilometers. 
As discussed previously, the in-situ production of propellants requires the capability of propellant scavenging from Altair's descent stage to provide hydrogen and oxygen, ISRU oxygen production to provide oxygen to optimize propellant scavenging and oxidizer for propellant, and the presence of humans at the outpost to provide carbon needed to produce storable fuel. Figure 13 shows the propellant required for a roundtrip mission versus the distance traveled for various hopper sizes and the propellant available at the end of each mission, for example 1,800 $\mathrm{kg}$ of propellant has been accumulated between mission 9 and 10. The propellant analysis begins in mission 9 because it is assumed that the outpost offers enough infrastructure and resources to support in-situ propellant production. Early missions (i.e. mission 10 thru 18) offer a fraction of the propellant capable at later missions due to the limited carbon source in the earlier mission as discussed in the in-situ fuel production section. The production of propellant ramps quickly to its maximum of $4,000 \mathrm{~kg} / \mathrm{yr}$ starting in mission 19 due to the permanent presence of humans at the outpost.

Figure 13 (a) shows propellant requirement for small to medium class hoppers and propellant accumulated in small missions increments (i.e. once per Earth-year); whereas Fig. 13 (b) shows propellant requirement for medium to large class hoppers and propellant accumulated in large missions increments (i.e. twice per Earth-year). Earlier than mission 19, smaller robotic hopper can be supported for long hop distances or larger hoppers for short hop distances. These results would suggest that the hopper capability can take an evolutionary approach, where simple smaller missions are performed earlier and increase in objective and complexity as the hopper capability and outpost mature. A complete analysis of the hopper size, mission objectives, and propellant availability could be a paper of its own, thus, a summarization of its features here do not do justice to the true benefits of its capability. However, the intent here is to demonstrate the immense possibility a water-rich outpost and all the resulting capabilities offered to science and exploration missions.

\section{Change in Energy Storage \& Power Architecture}

The optimization of the production and reclamation of water in the lunar outpost offers a new trade for the energy storage and power architecture. In the sense of energy storage and power systems, water can be seen as the source energy in the form of hydrogen and oxygen used in a fuel cell power generation system. Furthermore, in close-loop regenerative fuel cell (RFC) system, water is a reusable energy source.

Fuel cell systems (based on Proton Exchange Membrane technology) without any regenerative capability (i.e. no solar arrays or regenerative portion of the fuel cell) are anticipated to have an specific energy of about $800 \mathrm{~W}-\mathrm{hr} / \mathrm{kg}$ for the assumed energy and power level (about $840 \mathrm{kw}-\mathrm{hr}$ for the 14 day excursion and $2.6 \mathrm{~kW}$ ) and storage of reactants as liquids, which will be discussed further later. Recharging along the way or using solar power to supplement the energy storage power complicates the estimation. Other assumptions such as redundancy of tanks and possibly reactants and other margins as well as reactant storage type (gaseous, supercritical, or liquid) can affect the results. Liquid is lighter than supercritical storage due to the pressure levels of each. Gaseous storage is more practical (both mass and volume wise) for lower energy levels. The power usage and thermal requirements to maintain the storage of reactants requires further analysis to better scope the storage trade.

Specific energy is, of course, a strong function of energy usage. If the LER excursion duration was assumed to be less than 14 days, even though less reactants are needed, the tank mass is the same since it is assumed the tanks are sized for the worst case trip (unless smaller tanks can be added/removed rather than have one or two larger tanks). For much less than 14 days, the specific energy of the fuel cell system approaches that of the battery system. Assuming fixed tanks/tank size (sized for the worst case of 14 days), with only 7 days of operation, the specific mass goes to $\sim 500 \mathrm{~W}-\mathrm{hr} / \mathrm{kg}$ since you must still carry the same tank size. Similarly, the results for 3 days are $\sim 250 \mathrm{~W}-$ $\mathrm{hr} / \mathrm{kg}$ and for 2 days $\sim 180 \mathrm{~W}-\mathrm{hr} / \mathrm{kg}$. In contrast, batteries under development for the lunar surface (based on lithium ion technology) are anticipated to have from $150 \mathrm{~W}-\mathrm{hr} / \mathrm{kg}$ specific energy at the battery level. The specific energy for a battery system (including mass margin) is $\sim 100 \mathrm{~W}-\mathrm{hr} / \mathrm{kg}$ if you ignore recharge. By including recharge effects using a solar array, this value can go up to $\sim 150 \mathrm{~W}-\mathrm{hr} / \mathrm{kg}$ for slow LER travel over a maximum driving time/day (drive 12 hours/recharge for 12 hours) to $280 \mathrm{~W}-\mathrm{hr} / \mathrm{kg}$ for maximum speed LER travel (drive 2 hours/recharge for 22 hours).

Given the higher energy density from fuel cell and regenerative fuel cell systems over a battery system, the effects of a (a) fuel cell-based PUP, (b) regenerative fuel cell-based PUP, and (c) fuel cell-based LER options were considered during the enhanced scenario analysis. A RFC-based LER was not considered this time due to the challenges and high risks envisioned for a large light-weight, high-efficiency, and deployable solar array required for fast fuel cell reagent regeneration in a mobile platform. The baselined Scenario 12 has already incorporated a RFC-PSU; hence, the following mobile energy storage and power system options assume an RFC-PSU at the outpost.

17

American Institute of Aeronautics and Astronautics 
The following options are available for the three element variation listed above:

a. Fuel cell Portable Utility Pallet:

If sufficient reactants are available, the PUP may not require a regenerative system to support a 14 day excursion. In this case, the electrolysis hardware could be eliminated, reducing the overall mass and complexity of the PUP. The fuel cell PUP has the potential to increase the energy storage capacity with no change in mass, or provide a significant mass reduction at the same energy storage level.

b. Regenerative Fuel cell Portable Utility Pallet:

At higher storage capacities, the RFC-PUP system is more mass efficient than batteries. For approximately the same mass as the $100 \mathrm{kWh}$ battery-based PUP, an RFC-PUP can provide nearly three times the energy storage capacity. With the regenerative fuel cell and appropriate water and gas transfer hardware, the PUP could also provide electrolysis services for other fuel cell-based systems, thus potentially reducing overall mass across the architecture. The PUP's RFC could also be used to support other surface operations by converting the water to consumable $\mathrm{O}_{2}$ for crew use or into propellants.

c. Fuel cell Lunar Electric Rover:

The baselined LER design is powered by a battery energy storage and power system, which requires and external power regeneration system to recharge the batteries (e.g. PSU and PUP). A fuel cell-based LER would either reduce the mass of the overall element or significantly increase the energy storage capacity for the same element mass. The fuel cell-based LER would still require the support of PSU and PUP, but this time the LER would transfer water to the support units and the support units would transfer fuel cell reagents to the LER, minimizing recharge time.

The combination of these surface system element variations proposed for the water enhanced scenario introduces a new campaign optimization opportunity. A combination of fuel cell PUP and battery LER provides a mass reduction or increase of energy storage on the PUP element. However, this option may introduce system complexity and incur additional developmental cost because of the two different energy storage and power system. The same disadvantage holds true for a battery PUP and a fuel cell LER. In the combinations: battery PUP and fuel cell LER as well as in fuel cell PUP and fuel cell LER, the PUP's energy storage and power system is sized to only provide operational power to the PUP, eliminating the energy storage required to recharge the LER. The fuel cell LER will exchange fuel cell reagents and water with the PUP, which functions as an extended fuel cell reagent and water storage unit in order to keep the LER mass to a minimum helping to reduce driving power requirements. A similar concept of operations of exchanging reagent and water will be required in a regenerative fuel cell PUP and fuel cell LER combination. The disadvantage of this option is the fast regeneration of fuel cell reagents required, which will need a large mobile solar array system on the PUP to keep up with the demand for fuel cell reagents.

Each of the combinations of PUP and LER provide their own advantages and disadvantages. One of the objectives of this analysis was to identify possible mass savings to the campaign by implementing a change in energy storage and power system architecture based on the availability of excess water, which make the use of fuel cell systems more attractive. Table II compares the mass and energy storage of the battery-based and the fuel cellbased PUP, which result in a mass savings of approximately $500 \mathrm{~kg}$ at an energy storage level of $100 \mathrm{~kW}-\mathrm{hr}$. On the other hand, assuming a maximum system mass of $1,500 \mathrm{~kg}$, which is the mass allocated to a batterybased PUP in the baselined Scenario 12, the fuel cell-based PUP increases the energy storage capability by $150 \%$. In the same manner, a fuel cell LER would introduce an estimated $200 \mathrm{~kg}$ mass reduction from the baselined battery LER. Because the LER and PUP are delivered in pairs in a single cargo mission to the lunar surface (see manifest in Fig.-8), the total mass savings to Table II. Portable Utility Pallet Comparison. Mass and energy comparison of battery- vs. fuel cell-based Portable Utility Pallet

\begin{tabular}{|c|c|c|}
\hline & $\begin{array}{c}\text { Mass of System } \\
\text { at } \mathbf{1 0 0} \mathbf{~ k W}-\mathbf{h r} \\
\text { energy storage }\end{array}$ & $\begin{array}{c}\text { Energy Storage } \\
\text { at a mass limit } \\
\text { of 1,500 kg }\end{array}$ \\
\hline Battery PUP & $1,500 \mathrm{~kg}$ & $100 \mathrm{~kW}-\mathrm{hr}$ \\
\hline Fuel Cell PUP & $920 \mathrm{~kg}$ & $250 \mathrm{~kW}-\mathrm{hr}$ \\
\hline
\end{tabular}

mission 4 is approximately $1,400 \mathrm{~kg}$. Similarly, mission 6 and mission 9 can reduce the manifested mass by $400 \mathrm{~kg}$ and $1,000 \mathrm{~kg}$, respectively. These are significant mass reductions that could be utilized 
by other payloads that may have not been delivered earlier due to mass constraints in each of the mission. It should be noted at this time that this analysis has only investigated the mass savings of introducing advanced technology for energy storage and power systems. Other aspects, such as Con-Ops, risk, reliability, and others, have yet to be investigate to understand the overall benefit provided by these assumptions.

The availability of methane and oxygen to the energy storage and power system could introduce yet another dimension to the system trade space (i.e. storage of fuel cell reagents in the liquid state). Even though typical fuel cells don't operate with methane as the fuel reagent, methane could easily be broken into carbon and hydrogen. Given the mass and volume reduction provided by a liquid reagent storage architecture and the challenges of storing hydrogen in the liquid state, this approach should be considered. Hydrogen can easily be produced from the thermal decomposition of methane at temperature greater than $1,200 \mathrm{~K}$. However, the methane decomposition temperature requirement can easily be reduced to $723 \mathrm{~K}$ in the presence of a catalys ${ }^{17}$. This lower temperature can be achieved by a solar concentrator or resistive heater on the surface of the Moon.

Previous flight vehicles have stored life support oxygen in a gaseous or a supercritical state. Current Space Shuttle designs for life support oxygen are gaseous, but these are fairly large and, when combined with the oxygen required for fuel cell usage, might not be efficient for a lunar mission. A more compact option is supercritical oxygen, which is at a pressure higher than the critical point (5 MPa or $725 \mathrm{psi}$ ), but is tanked as a liquid and is typically stored so that it is cold while being used. Super-critical oxygen is used in the Shuttle's power reactant storage (PRSA tanks), but they are designed for a much shorter mission than the anticipated 6 month long lunar mission requirement. Subcritical LOx, which is oxygen at pressures below the critical point and is the densest of the three options described, also has storage limitations, since its boiling point is much lower than the expected environmental temperatures, causing it to over-pressurize its holding tank with time. However, with proper thermal control design to overcome boil-off, it can reduce system mass and volume over its gaseous counterpart. Subcritical LOx thermal control concepts have been identified that would meet the extended dormancy requirement expected for lunar operations. This can be achieved with passive thermal control, if the LOx is tanked at low temperatures and the thermal environment is less than approximately $237 \mathrm{~K}$. Thermal models show this will occur if a lunar shade is included at a lunar pole location, as that can isolate a deep space view on the top of the tank. For high environment temperatures, cryocoolers need to be integrated with the LOx tank. If the cryocooler is sized for the maximum expected thermal load, and given its ten-year expected lifetime, its use offers the flexibility to meet all the thermal environment requirements and to handle delays or anomalies in the mission timeline. The active cooling case is the lowest mass and lowest volume concept considered. This brief cryogenic storage discussion has been directed to storing LOx, as it has a lower boiling point than methane (i.e. $22 \mathrm{~K}$ lower). In theory, the same technique used for $\mathrm{LOx}$ storage can also be utilized for $\mathrm{LCH}_{4}$ storage. The storage of fuel cell reagents in the liquid form has the potential to provide an immense energy storage capability in the lowest mass and volume over gaseous storage, and the lowest technical challenge option (i.e. $\mathrm{LCH}_{4}$ ) beyond any other reagent storage options.

\section{Enhanced Scenario 12 Campaign}

The objective of this study was to perform an analysis of the capabilities that may become available to the lunar architecture with the availability of water, and its effect to current Scenario 12 campaign. It has been discussed that the availability of water unlocks a new energy storage and power system architecture, introduces in-situ propellant production (including fuel), and enhances exploration and science missions with the use of hoppers. When compared to the baselined Scenario 12, the changes in the energy storage and power system provides a mass saving totaling to $2,400 \mathrm{~kg}$.

The use of robotic hoppers, resulting from the capability to produce propellants at the outpost, would significantly enhance the exploration and science objectives of the lunar outpost campaign. The global reach of these hoppers could reduce or eliminate the need of human sortie missions, which represent a delay to the outpost build-up and a significant cost to the overall lunar program. Assuming that the objectives of human sortie mission can be fulfilled by robotic hoppers, and these sortie missions can be delayed a few years once the hoppers are fully operational, the resulting changes to the manifest are shown in Fig. 14. This analysis suggests that the outpost could be built at a faster pace, and continuous human presence on the Moon could be reached about a year sooner. Timewise, this is not a significant improvement; however, the exclusion of four human sortie missions from the lunar exploration program provides a significant cost reduction to the program.

One question remains: can the same scenario 12 manifest support the added elements given the relative small mass available (i.e. 2,400 kg freed-up by the energy storage and power architecture)? Perhaps, it could be accomplished. First, we assume a hopper dry mass of approximately $1,000 \mathrm{~kg}$, and of it $750 \mathrm{~kg}$ is the mass of the hopper's propulsion system and structure. This hopper can be manifested in mission 4 , which has a potential mass available of $1,400 \mathrm{~kg}$, this is shown by mass reduction labels in Fig. 14. The hopper would provide a standard 
payload interface to allow for science payload exchange, the infrastructure for heavy-lift operations is available at the outpost (i.e. SOD or LSMS). Second, assume $250 \mathrm{~kg}$ of the science mass allocation in mission 4 is allocated to the science package for the hopper. Note that each mission has a total of $500 \mathrm{~kg}$ mass allocated to science, which could provide several $250 \mathrm{~kg}$ science packages that could be exchanged onto the hopper. At this point, we have a science hopper on the surface of the Moon, and have only utilized $30 \%$ of the mass available. The remainder mass available could be used to manifest the fuel production element and hopper ground support equipment such as: propellant transfer equipment, launch and landing aid, etc. This is certainly a challenge, but not impossible given today's technologies.

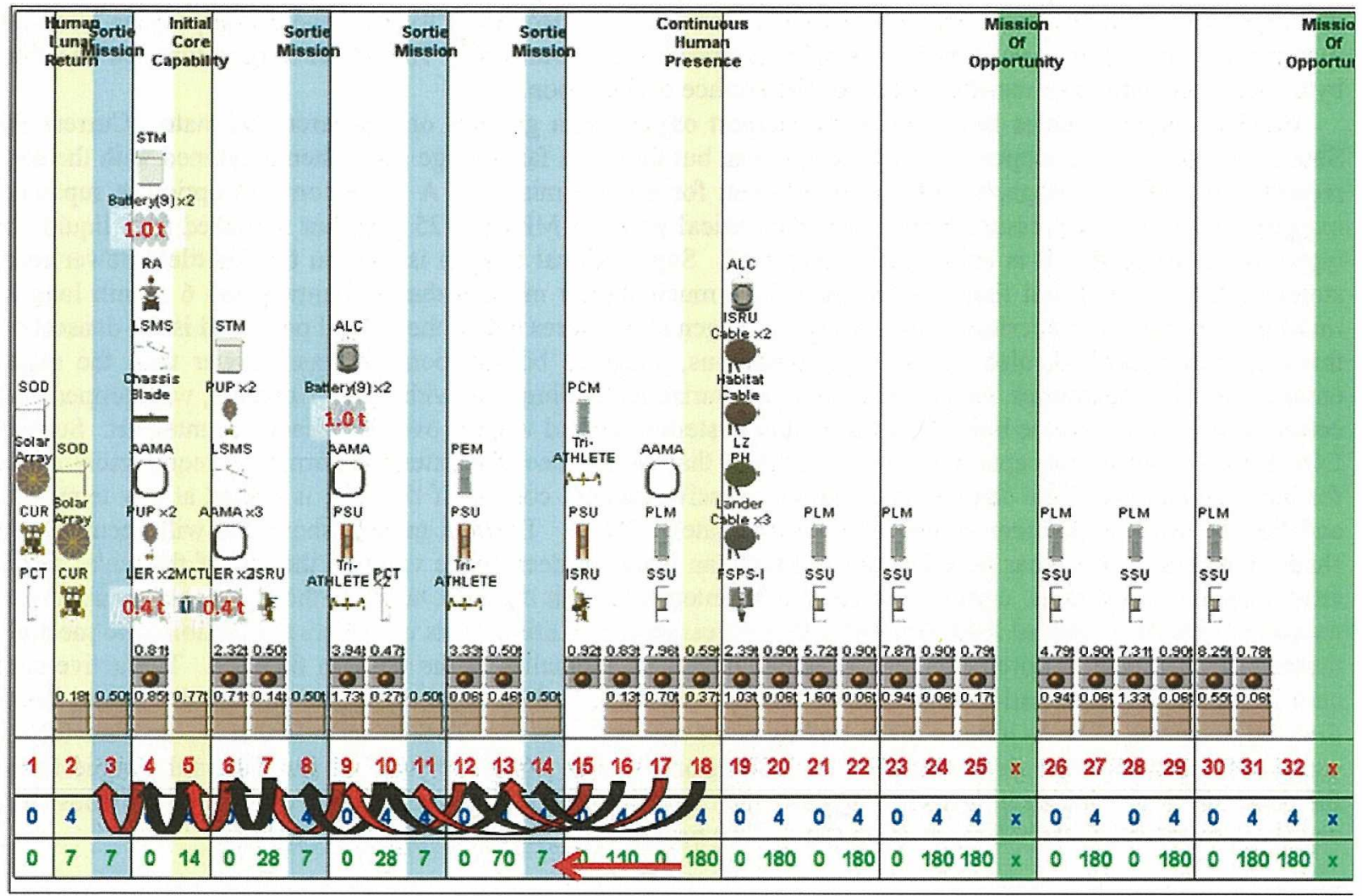

Figure 14. Enhanced Scenario 12 manifest. Changes to the baselined Scenario 12 manifest showing the outpost build-up sequence if sortie missions are eliminated and the mass savings by the change in energy storage and power system architecture.

\section{Conclusions}

This study demonstrate the significant impact and revolutionary options to enhance the lunar architecture's science and exploration mission objectives offered by the availability of water at the lunar outpost. Optimizing the water produced from Altair descent stage propellant scavenging by using ISRU $\mathrm{O}_{2}$ can double the amount of water produced per mission, providing a source for fuel cell reagents (hydrogen and oxygen). The use of high energy density fuel cell systems, instead of battery systems, provides significant reduction of Earth-launched mass that can be available to other elements. The availability of hydrogen makes possible the production of storable fuel (i.e. methane), when combined with carbon produced by humans at the outpost. This provides a continuous supply of fuel, since hydrogen is continuously delivered to the surface of the Moon with each mission and carbon will be produced while human are present at the outpost. This continuous supply of propellants (assuming oxidizer is produced from indigenous regolith) provides the capability of using robotic hoppers to provide supplies to LER excursion to extend range and provide "safe-haven" in a contingency situation, enhance the science and exploration mission objectives by integrating science payloads onto the hoppers, and prospect for sites of interest prior to sending humans to those sites that prove to be of more interest. 
This study does not perform a detailed analysis of all the possible impacts to the overall architecture; however, it does provide information of the potential benefits and enhancement to the lunar architecture if a more aggressive approach was assumed to the utilization of those resources available as a product of human exploration, as well as indigenous resources.

\section{Acknowledgments}

The authors gratefully acknowledge the support by the Lunar Surface System Project Office and the Domain System Engineers and Leads that made this study possible.

\section{References}

${ }^{1}$ Ewart, M. K., D. J. Barta, and J. McQuillan., "Exploration Life Support Technology Development for Lunar Missions," AIAA Space 2009 Conference and Exposition, AIAA- 2009-6448, Pasadena, CA, 2009

${ }^{2}$ Linne, D. L., et al., "Feasibility of Scavenging Propellants from Lander Descent Stage to Supply Fuel Cells and Life Support," AIAA Space 2009 Conference and Exposition, AIAA- 2009-6511, Pasadena, CA, 2009

${ }^{3}$ Mazanek, D. D., P.A. Troutman, C. J. Culbert, M. J. Leonard, and G. R. Spexarth., "Surface Buildup Scenarios and Outpost Architectures for Lunar Exploration," 2009 IEEE Aerospace Conference, IEEEAC 1093, Version 7; LF99-8045, Big Sky, Montana, 2009

${ }^{4}$ Gustafson, R.J., B. C. White, and M. J. Fidler., "Demostrating Lunar Oxygen Production with the Carbothermal Regolith Reduction Process". Paper No. AIAA 2009-663. AIAA Aerospace Science Meeting. Orlando, FL, Jan. 5-8, 2009.

${ }^{5}$ Sibille, L., et al., "Recent Advances in the Scale-up Development of Molten Regolith Electrolysis for Oxygen Production in Support of a Lunar Base.” Paper No. AIAA 2009-659. AIAA Aerospace Science Meeting. Orlando, FL, Jan. 5-8, 2009.

${ }^{6}$ Caruso, J. J., et al., "Excavation on the Moon: Regolith Collection for Oxygen Production and Outpost Site Preparation". Paper No. AIAA 2008-808. 46 AIAA Aerospace Science Meeting. Reno, NV, Jan. 7-10, 2008.

${ }^{7}$ Clark, D. L., R. Patterson, and D. W. Wurts., "A Novel Approach to Planetary Regolith Collection: the Bucket Drum Soil Excavator.". Paper No. AIAA 2009-6430. AIAA Space 2009 Conference \& Exposition. Pasadena, CA, Sept. 14-17, 2009.

${ }^{8}$ Mueller, R. P., et al., "Lightweight Bulldozer Attachment for Construction and Excavation on the Lunar Surface". Paper No. AIAA 2009-6466 presented to the AIAA Space 2009 Conference \& Exposition. Pasadena, CA, Sept. 14-17, 2009.

${ }^{9}$ Carrier III, W. D., G. R. Olhoeft, and W. Mendell., "Physical Properties of the Lunar Surface." in Lunar Sourcebook (G. Heiken, D. T. Vaniman, and B. M. French, eds.), Cambridge, NY. 1991.

${ }^{10}$ Merrill, R. G., Andraschko, M., Stromgren, C., Cirillo, W., Earle, K., Goodliff, K. "A Comparison of Probabilistic and Deterministic Strategic Analysis for Human Space Exploration", AIAA Space 2008 Conference \& Exposition, San Diego, California, 2008

${ }^{11}$ Andraschko, M., Merrill, R. G., Earle, K., "Logistics Modeling for Lunar Exploration Systems," AIAA Space 2008 Conference \& Exposition, San Diego, California, 2008

${ }^{12}$ Chepko A. B., W. Crossley, D. Linne, E. Santiago-Maldonado, Olivier de Weck. "Architecture Modeling of In-Situ Oxygen Production and its Impacts on Lunar Campaigns." AIAA-2008-7823. AIAA SPACE 2008 Conference and Exposition, San Diego, California, Sep. 9-11, 2008

${ }^{13}$ Parrish, C., "Final Report Production of Methane and Water From Plastics and Crew Waste," C Parrish Consulting, NASA Contract Number NNK07EA25P

${ }^{14}$ Santiago-Maldonado, E., J. Captain, R. Devor, and J. Gleaton,. "Creating Methane from Plastic: Recycling at a Lunar Outpost." Paper No. AIAA 2010-1551. 48 th AIAA Aerospace Sciences Meeting Orlando FL, January 4-7, 2010.

${ }^{15}$ Stanley, D., "NASA's Exploration Systems Architecture Study," NASA-TM-2005-214062. Washington, DC. NASA Headquarters, 2005

21

American Institute of Aeronautics and Astronautics 
${ }^{16}$ Condon, J., "Copernicus - Advanced Trajectory Design and Optimization System," Research Johnson Space Center [online database], URL: http://research.jsc.nasa.gov/PDF/Eng-12.pdf [visited on 26 July 2010].

${ }^{17}$ Choundhary. T. V., Sivadinarayana, C., Chusuei, C. C., Klinghoffer, A., and Goodman, D. W., "Hydrogen Prodcution via Catalytic Decomposition of Methane." Journal of Catalysis, Vol. 199, 2001, pp. 9-18. 